Portland State University

PDXScholar

Summer 9-3-2015

\title{
Inspiring Action: Measuring the Effect of Motivational Frames on Social Movement Mobilization
}

Rebecca Louise Smith

Portland State University

Follow this and additional works at: https://pdxscholar.library.pdx.edu/open_access_etds

Part of the Communication Technology and New Media Commons, and the Social Influence and Political Communication Commons

Let us know how access to this document benefits you.

\section{Recommended Citation}

Smith, Rebecca Louise, "Inspiring Action: Measuring the Effect of Motivational Frames on Social Movement Mobilization" (2015). Dissertations and Theses. Paper 2510.

https://doi.org/10.15760/etd.2507

This Thesis is brought to you for free and open access. It has been accepted for inclusion in Dissertations and Theses by an authorized administrator of PDXScholar. Please contact us if we can make this document more accessible: pdxscholar@pdx.edu. 
Inspiring Action:

Measuring the Effect of Motivational Frames

on Social Movement Mobilization

by

Rebecca Louise Smith

A thesis submitted in partial fulfillment of the requirements for the degree of

Master of Science

in

Communication

Thesis Committee:

Lauren B. Frank, Chair

Cynthia-Lou Coleman

Maureen O'Connor

Portland State University

2015 
(C) 2015 Rebecca Louise Smith 


\begin{abstract}
In order to probe how social movement messages foster participant mobilization, this study utilized an experimental design to investigate collective action frames, core messaging tasks that define problems, assign blame, convey a plan of action, and inspire participation. The study compared the effects of climate change messages that contain motivational frames with those that do not, incorporating the influence of resonance, and exposure to competing and counter frames. Results revealed that motivational frames contributed to mobilization, especially intention to act, under conditions of resonance and with exposure to counter frames. Salience primed participants to respond to motivational frames, however for some, motivational frames decreased intention to act. As social movements and climate change continue to profoundly shape our world in myriad ways, we will be better prepared to address those changes with information provided here.
\end{abstract}




\section{Dedication}

I dedicate this work to my mother, Anne Warren Smith (July 3, 1938 - March $13,2015)$. As a writer, she taught me that communication is both a science and an art. While much can be learned, there is always part that requires creativity and intuition. While I have been gifted with much knowledge about communication through the program at Portland State University, my mother has been the inspiration for my creativity and trust in my intuition.

My mother also taught me that whatever my present circumstances may be, those circumstances do not need to stand in the way of fulfilling my dreams. As she might have said, in reference to her own mother's clothing and life choices, we do not have to stay inside our girdles. I watched again and again as she grew out of so many restricting situations: that of obedient daughter, housewife, divorcee, cancer survivor... She ripped out the seams of every restrictive garment and remade it into flowing attire. Through this witness I understood that it was up to me to fashion my life as I could. As I move from graduate school to a new job, it will be the first time she will not be present to lend her encouragement and wisdom to my latest alteration. Her courage, inspiration, and love, however, remain with me forever. 


\section{Acknowledgements}

I gratefully acknowledge my committee for their assistance with this work. Dr. Coleman provided a wealth of knowledge on framing and pushed me to deepen my comprehension of core concepts. Professor O'Connor contributed a valuable marketing perspective and inspired inclusion of an overlooked but important component of the work. Dr. Frank contributed expertise in behavior change, social change, and quantitative analysis. But perhaps most importantly, she also provided tremendous support. Whenever I entered her office confused or unsure, I left feeling excited and ready to take on the next task. When life events conspired to throw me off track, she was generous with her time to make sure I could complete my thesis on schedule. I could not have asked for a better chair.

I also wish to thank my husband, Christopher, for every meal cooked, every load of laundry washed, and every concern hugged away. Having him by my side on this adventure made the challenges more bearable and the victories sweeter. I am deeply grateful to have a life partner who is willing to give so much to see me succeed. 


\section{Table of Contents}

Abstract.

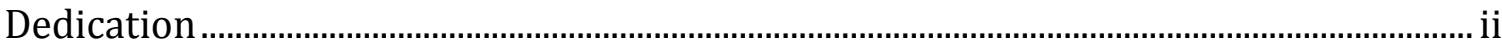

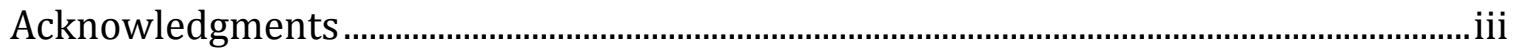

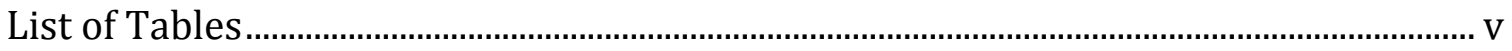

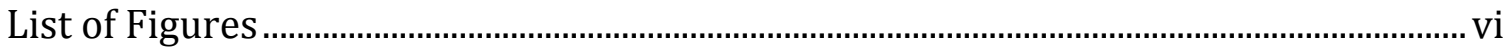

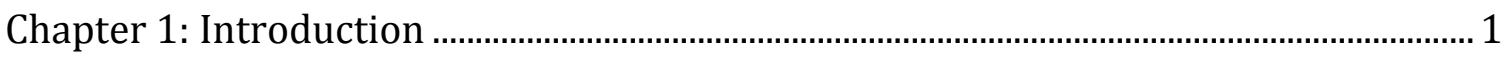

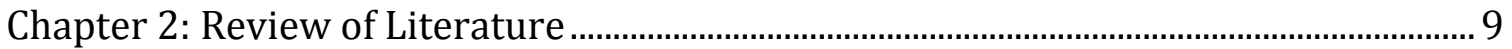

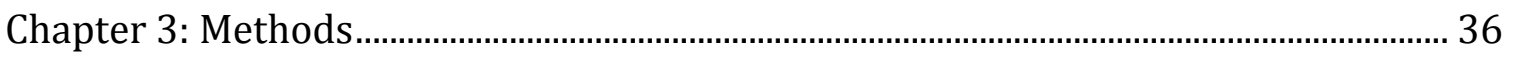

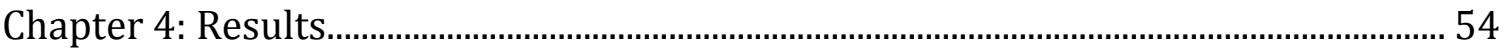

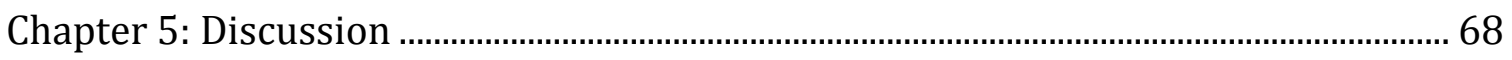

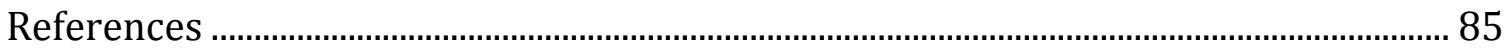

Appendices:

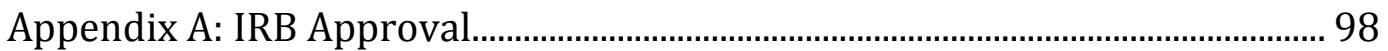

Appendix B: Demographic Statistics.................................................................... 100

Appendix C: Informed Consent ..............................................................................101

Appendix D: Video Transcripts ............................................................................ 103

Appendix E: Survey Instrument................................................................................107 


\section{List of Tables}

Table 1: Rotated Component Matrix for 24-Item Attitude Scale ..................................... 44

Table 2: Final Attitude Scale - Rotated Component Matrix for 8-Items......................... 46

Table 3: Behavioral Intention and Efficacy of Cooperation Scales................................. 48

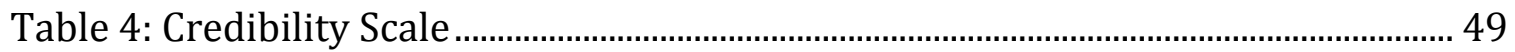

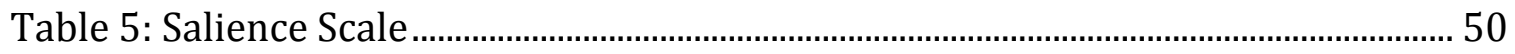

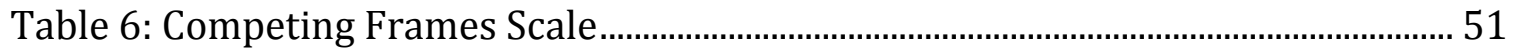

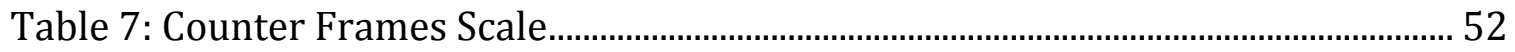

Table 8: Spearman's Rho Correlations within Mobilization Measures and within

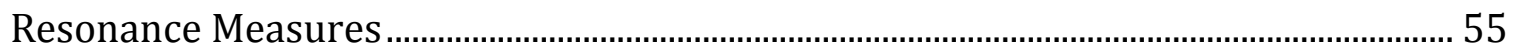

Table 9: Spearman's Rho Correlations among Mobilization and Resonance Measures

Table 10: Regression Models Predicting Mobilization Intention..................................... 64 


\section{List of Figures}

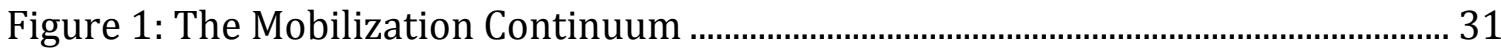

Figure 2: Hypotheses and Research Questions Depicted on Mobilization Continuum

Figure 3: Estimated Marginal Means for Prospectives on Intention to Act Scale....... 67

Figure 4: Results Depicted on Mobilization Continuum ..................................................... 69 


\section{Chapter 1: Introduction}

In the mid-1980s, I joined a social movement working toward nuclear disarmament. I was a college student, and my top priorities were partying with friends and getting reasonably good grades. One afternoon during my sophomore year, I found myself staring at a poster in the student center inviting me to a meeting to learn more about The Great Peace March. I knew right then, I was going. What enticed me to drop out of college and join a group of 5,000 unfamiliar people in a cross-country peace march? What were the messages on that poster that rang so true that I felt the need to change my trajectory? What effect did past experiences, world events, and cultural narratives have that prepared me for that moment of taking action? While the group turned out to be one-tenth its planned size and global disarmament did not take place immediately after we marched into Washington D.C. after a nine month trek, the adventure was an ongoing experiment in creating and shaping messages with the thousands of people we met along the way in order to inspire changes in attitude and engagement in collective action. Profound repercussions of the march are still felt today, as many of the 500 marchers continue to participate actively in hundreds of issues from peace to domestic violence prevention to climate change mitigation, creating marches, lobbying legislators, training activists, and much more.

Social movements, often starting as informal gatherings of citizens, can grow into an influence larger than each person combined, establishing new laws, institutions, and even governments, as the American Revolution did (Fahlenbrach, 
Sivertsen, \& Werenskjold, 2014; Madestam, Shoag, Veuger, \& Yanagizawa-Drott, 2013; Meyer, 2009). At the same time, many movements gain momentum only to dissipate, leaving no noticeable mark, such as the Rajneesh spiritual movement that flourished in Oregon in the early 1980s, only to disappear just four years later (Palmer, 1988). Scholarly investigation about what has made some social movements effective at meeting their outcomes while others have failed has spanned more than half a century of inquiry across many continents. Current communication inquiry on social movements often focuses on framing efforts by movement actors and potential constituents: how actors shape their messages to engage audiences and what inclines individuals to respond.

Collective action is an inherent part of social movements. Collective action is defined as a collection of individuals acting as a cohesive unit, whether physically present or not, in which they have adopted a shared definition of a problem (Klandermans, 2014). Mobilization is equally important. Mobilization is the process of persuasion that creates support for a cause's viewpoints and/or inspires active participation in a cause through material or non-material means (Klandermans, 1984). Mobilization is considered an important measure of outcomes because without mobilization, collective action would not occur (Klandermans, 1984; 2014).

A current worldwide social movement centers on climate change. Climate change (a.k.a. global warming) has been established as a global problem with farranging and severe consequences such as widespread drought, floods, extreme weather, species extinction, sea level rise, breakdown of civil infrastructure, and 
more (IPCC, 2014). The fact of anthropogenic climate change is not in doubt; a study examining almost 12,000 peer-reviewed abstracts over 20 years found that over $97 \%$ of studies that took a position agreed that climate change is caused by human activity (Cook et al., 2013). The seriousness of climate change has inspired a social movement made up of hundreds of organizations and thousands of actors in the United States and worldwide.

One organization that has been active in the climate change social movement is 350.org, founded by scholar Bill McKibben. The goal of this United States-based grassroots organization is to move atmospheric carbon dioxide levels from 400 parts per million to below 350 ppm (“Bill McKibben," 2012; “What we do," n.d.; Mitra, 2013), the safe concentration to avoid irreversible climate change based on climate science research (Hansen et al., 2008). The organization works in a distributed fashion using online coordination to create offline action through community organizers in every country except North Korea. The purpose of its activities is to raise awareness about climate change and create climate solutions. Organizers' endeavors range from one-time coordinated worldwide actions such as the People's Climate March held in September 2014 to ongoing local projects such as convincing Norway's largest pension fund to divest from coal investments ("Bill McKibben," 2012; “Fossil free Europe," n.d.; "How we work," n.d.; “What we do,” n.d.).

Despite work by organizations like 350.org and the risks associated with climate change, the issue has received lukewarm support from those able to have an 
effect on the problem, such as the general public and governments. A Gallup poll conducted in spring 2014 showed that only 33\% of Americans surveyed view climate change as a cause of serious concern, placing climate change at the bottom of a list of environmental concerns. This number has changed little in the 13 years Gallup has conducted this poll (Newport, 2014). As of spring 2013, 63\% of Americans believed that there is solid evidence of climate change, a number that has been fluctuating, but overall decreasing, in the most recent five years of polling data; the highest level recorded was the fall of 2008 at 72\% (Rabe \& Borick, 2013). A spring 2014 Gallup poll showed just 57\% surveyed believe humans are the cause of the Earth's warming (Saad, 2014).

Given the seriousness and the fluctuation in belief in the issue, researchers have been motivated to explore why people have not taken more actions to curb climate change on their own. Barriers to participation include skepticism due to lack of trust in scientific and government institutions (Gifford, 2011), fatalism due to a sense that the problem has moved beyond human control (Lorenzoni, NicholsonCole, \& Whitmarsh, 2007), and a concerted effort by an elite few to undermine scientific consensus (Oreskes \& Conway, 2010). In fact, the more information people have about climate change, the less concerned and responsible they feel (Lorenzoni \& Pidgeon, 2006). This could be due to the fact that "over time, people who are repeatedly exposed to uncontrollable negative life events learn to 'give up,' becoming helpless and, eventually, hopeless" (Berry, Hogan, Owen, Rickwood, \& Fragar, 2011, p. 125S). Additionally, climate change can seem a distant abstraction 
to many, with effects such as sea level rise too far in the future to worry about (Myers, Maibach, Roser-Renouf, Akerlof, \& Leiserowitz, 2013). These are just some of the challenges facing social movement organizations working to mobilize supporters to impact climate change. Bill McKibben, founder of 350.org, is well aware of these challenges: "In the end, the problem is not, at its root, lack of understanding. There's a lack of will to act..." (“Bill McKibben,” 2012, p. 4).

On the other hand, people become more influenced by issues when those concerns seem personally relevant. Individuals find it easier to assess large problems when they can relate them to their own experiences (Egan \& Mullin, 2014). Americans with direct experience of the effects of global warming have increased perceptions of risk, worry, and motivation (Myers et al., 2013). The weather people experience, particularly hot weather even when not scientifically attributable to climate change, has been shown to directly impact their belief in climate change (Zaval, Keenan, Johnson, \& Weber, 2014). This connection is due to retrievability bias; recent experiences in people's minds tend to overshadow rational judgments (Tversky \& Kahneman, 1974; Zaval et al., 2014). "Place-based climate change education strategies — which highlight the local impacts of climate change in a manner that can be experienced by people with their senses-hold considerable potential to help large numbers of Americans come to understand the issue in a manner more consistent with the state-of-the-science" (Myers et al., 2013, p. 345). Retrievability bias presents both problems and opportunities for organizations like 350.org. While it is hard for someone in New York to understand 
what it means to have to migrate from a remote Pacific island due to sea level rise (Birk \& Rasmussen, 2014), that same person could respond to a span of extreme weather such as the 2009-10 record Atlantic region winter snowfalls that 350.org framed as a likely result of climate change ("Printable materials: Climate impacts fact sheets," n.d.).

Social movements matter. They affect public policy, political, economic, and social institutions, and the people who participate (Meyer, 2009). Historically, social movements have been at least in part responsible for changes large and small including the overthrow of tyrannical governments and passage of state laws on gun safety. Given the power of social movements, understanding how movement communication processes affect outcomes is constructive, both for the purposes of communication research and for practical application in movement organizations.

\section{Study Overview}

Following the work of social movement framing scholars such as Benford and Snow, I investigated collective action frames, the three strategic framing tools that movements use to diagnose a problem, provide a prognosis, and inspire action. Approaching the issue in a way that appears not to be addressed in academic literature, I compared participant mobilization responses to experimental manipulations of texts that contain some or all of these framing tools. I also measured potential moderating factors such as counter and competing frames and frame resonance, the interaction between the framing of texts, the external culture, 
and participants' internal schema. I used the current social movement on climate change as my illustrative example.

This thesis aimed to add to the rich body of social movement framing research by investigating the micro- and meso-level strategic communication practices of social movement actors. By looking at the interaction between potential constituents and climate change movement texts, I sought to further illuminate the triggers that inspire collective action, moving an actor to mobilization. Chapter 2 will first provide an explanation of message and cognitive framing and explore in more depth the role of cognitive framing in message processing. I then outline a brief history of the study of social movements and the emergence of framing as a theoretical basis for study within that field. I define several important terms such as collective action frames and frame resonance that shape the work herein, and propose my hypotheses. In Chapter 3, I explain the methodology used to test my research questions. I proceed to present and examine the results of the data in Chapter 4, comparing responses from those exposed to texts containing motivational frames to responses from those who were not exposed, incorporating variables such as resonance and counter frames. Results showed that motivational frames contributed to mobilization, especially intention to act, under conditions of resonance and with the presence of counter frames, but were not indicated in a direct relationship with mobilization. Lastly, in Chapter 5, I discuss the results, exploring the relationship between motivational frames, resonance, and counter frames, as well as the potential influence of the sample. Study outcomes indicate 
that heightening resonance and acknowledging counter frames in social movement messages could potentially address barriers to participation. The discussion also addresses further implications for the social movement field of study as well as limitations and practical applications. 


\section{Chapter 2: Review of Literature}

\section{Framing}

Although framing is a mechanism that people encounter and use every day, we are not necessarily aware of framing processes (Goffman, 1974), and there are several ways the term can be applied. Therefore, an explanation of the word is necessary. Entman, one of the foremost scholars on framing, defines the verb "to frame" as "to select some aspects of a perceived reality and make them more salient in a communicating text, in such a way as to promote a particular problem definition, causal interpretation, moral evaluation, and/or treatment recommendation" (Entman, 1993, p. 52).

According to Entman, as well as D'Angelo (2002), another framing scholar, there are at least four players in the framing process: "the communicator, the text, the receiver, and the culture" (Entman, 1993, p. 52). This delineation introduces the distinction between cognitive frames and message frames. Cognitive frames operate in the mind of the receiver and are created in part through culture; they exist as components of the mental store of experience and understanding that an individual continually builds and shapes during her interaction with others and the broader culture. These frames are used to organize and process information efficiently (D'Angelo, 2002). Message frames operate at the level of text and are created by the communicator, either purposefully or unintentionally, and refer to the culture. At the individual level, message frames interact with cognitive frames (Scheufele, 1999). Framing, therefore, can be understood as an interaction between those 
composing messages using message framing, and those receiving messages where messages interact with their cognitive frames.

Interaction between cognitive and message frames. Three interesting bodies of work investigate the link between message frames and cognitive frames. Petty and Cacioppo explored this interaction in their elaboration likelihood model (ELM) (1986), Kahneman examined these roles in terms of decision making (2013), and multiple researchers have investigated the role of rationally versus emotionally oriented messages and their effects on message acceptance.

The ELM posits that individuals process information in two different ways, via the central route and the peripheral route, depending on the level of critical thinking applied to an argument. Processing messages on the central route suggests that a person carefully scrutinizes an argument; processing on the peripheral route allows for a person to make quick assumptions about an argument. The theory also considers the attitude of the individual, the strength of the argument, and relevance to his or her life. Messages about which the individual is knowledgeable, is motivated to process, feels are relevant, and from which she is not distracted are likely to activate critical thinking, which uses the central processing route. Messages considered on this route will usually have bigger and longer-term impacts on persuasion than messages evaluated on the peripheral route. When individuals engage the peripheral route, they use heuristics such as credibility and likeableness to process persuasive messages. Persuasion can occur on the peripheral route but the results are usually more limited and shorter term (Petty \& Cacioppo, 1986). 
Kahneman also suggests two ways of processing persuasive messages, using what he calls System 1 and System 2 thinking. System 1 is the type of message processing that people use most often. It is fast, efficient, emotional, and uses heuristics to make judgments. System 2 processing is effortful, logical, and requires attention and energy to make deliberate choices (Kahneman, 2013). Individuals use System 1 processing by default, relying on simplified models of the world to help understand what is normal and to find associations between things, enabling people to organize and process information efficiently. System 1 uses heuristics to allow people to make quick judgments that can work efficiently, but can also mislead. System 2 thinking engages when it senses an imminent error or as soon as System 1 detects a violation of its simplified model of the world. System 2 requires focused attention to provide deliberative thought in order to critique a situation, engage rationality, and avoid the biases that System 1 wants to utilize. Some people are less apt to use System 2 thinking than others because they want to avoid cognitive effort (Kahneman, 2013).

Another way to look at two-system processing is to view messages as appealing to either rational or emotional schema. This division of message presentation between logic and emotion is often referred to in terms of cognitive appeals versus affective appeals. It should be noted that the term cognitive in this case has a different definition than in reference to cognitive framing. Cognitive framing, as explained above, entails activating the schema existing in the mind of the receiver, so the term cognitive refers to something that dwells in the mind. When 
speaking of cognitive appeals, however, the term refers to information that is rationally or logically oriented, such as facts and numbers, as opposed to something that is emotionally oriented, such as positive or negative feelings (Leiserowitz, 2006).

Much communication research has been devoted to the incorporation of cognitive and affective methods for influencing attitudes (e.g. Basil \& Witte, 2011; Fabrigar \& Petty, 1999) and articulation of persuasion processes (e.g. Nabi, 1999; Petty \& Cacioppo, 1986). Psychological research continues to refine our understanding of the ways our brains process these two types of information, recognizing that they are not polar opposites, but in fact interact to influence each other (Duncan \& Barrett, 2007).

Cognitive appeals are more effective with certain people or in certain contexts than affective appeals, and vice versa, although in some fields, research has shown that affective appeals overall have a larger influence on persuasion (Small, Loewenstein, \& Slovic, 2007). Edwards (1990) discovered that when people were cognitively primed, both affective and cognitive messages about a fictional beverage swayed attitudes, but when people were affectively primed, only affective messages had an influence. Similarly, Fabrigar and Petty (1999) found that when people's attitudes were primed affectively by tasting a beverage instead of reading about it, their attitudes underwent a larger change in response to affectively based persuasive messages. Mayer and Tormala (2010) found that for cognitively-oriented people, a message that used the word "think" was more effective at persuading 
behavioral intentions than the same message substituting the word "feel;" the opposite was true for affectively-oriented individuals.

Therefore, people's cognitive or affective orientation can affect the success of messaging. In addition, recent experiences can prime them to be more responsive to cognitive or affective messages. Both orientation and experiences influence the resonance of messages by interacting with existing schema that is cognitively or affectively oriented.

Affective and cognitive processing and Kahneman's System 1 and System 2 processing metaphor share many characteristics in common with Petty and Cacioppo's peripheral and central route processing metaphor. System 1 can equate to peripheral processing in its use of cues such as credibility, liking, heuristics, and affective appeals. System 2 can compare to central processing in its attention to argument strength, rationality, critical thinking, and cognitive appeals (Kahneman, 2013; Petty \& Cacioppo, 1986; Small et al., 2007).

Insights from these scholars illuminate how message frames interact with cognitive frames. According to these works, there are natural ways of processing that have developed through human evolution that affect how people receive and process messages, indicating that there may be deeply ingrained cognitive frames shaping responses. Additionally, some people are more inclined to use central, logical, and System 2 processing, while others depend almost entirely on peripheral, emotional, and System 1 processing, indicating that certain people may make use of certain cognitive frames, either due to inborn intelligence or learned experience, 
that others do not. Additionally, certain features of messages and message context trigger peripheral, affective, and System 1 processing, such as a distracting environment, a personal appeal, and a less relevant topic. Other features, such as motivation, topical knowledge, an abstract appeal, and a novel situation, trigger central, deliberative, and System 2 processing (Kahneman, 2013; Petty \& Cacioppo, 1986; Small et al., 2007). In this way, cognitive frames can shape message frames and vice versa. Given this information about cognitive frames, those wishing to influence others, such as social movement agents, can consider certain factors when composing messages: topic relevance, situational context, tendency toward critical or emotional processing, peripheral cues, background knowledge, recent experiences, and more.

\section{Social Movements}

Social movements have been defined as somewhat coordinated groups of people organized around a goal of creating or resisting change in a society, culture, or world order, that have a shared collective identity and maintain continuity over time (Diani, 1992; Snow, Soule, \& Kriesi, 2004). Social movement work typically takes place outside institutional venues, although organizations can play a large role in the advancement of social movement issues (Diani, 1992).

Social movements have been a rich source of data for researchers to mine. Much of the first published academic research on social movement participation in the 1950s and 1960s focused on social psychological theories that postulated why people were motivated to join social movements. "Social psychology is interested in 
how social context influences individuals' behavior" (Klandermans \& van Stekelenburg, 2007, p. 157). These early theories implied that participation in social movements was an irrational and deviant act because all movements seemed doomed to fail, and because participants were seen as lashing out, often violently, against society (Gamson et al., 1982; Schwartz, 1976). Many theories attempted to identify particular personality traits or social positions as driving factors. However, these theories were not supported when applied to the participants in the many and varied movements arising in the 1960s. Movement constituents were not just responding to irrational desires to fit in or reacting against the status quo, they were responding to rational justifications and decision-making processes (Klandermans, 1984, 2014; Noakes \& Johnston, 2005). Recognition of these inconsistencies led to the discrediting of social psychological approaches as a useful way to analyze movement participation in social movement research.

After a period throughout the 1970s where social movement studies targeted structural and organizational factors, scholars began to see in the 1980s that the neglect of social psychological factors left a major gap. Qualitative methods, popular among many movement researchers, are based the on concept of symbolic interactionism, as formulated by Blumer (1969). Symbolic interactionism is the idea that meaning is a social construction, created and recreated in the interactions between people, and should not be treated as static or given (Blumer, 1969; Giugni, 1998). Yet the structural and organizational theories researchers had come to rely upon contained assumptions in direct contradiction to these ideas. For example, 
resource mobilization theories assume that those being mobilized already hold beliefs that line up with the mobilizers instead of acknowledging that meanings and beliefs can be produced through interaction with mobilizers (Snow \& Benford, 1988). Additionally, scholars' conclusions lacked explanations for social psychological phenomena such as what inspired people to join movements and why movements were sustained even when political opportunities or resources were scarce (Gamson et al., 1982; Klandermans, 1984; Snow, Rochford, Worden, \& Benford, 1986). Social movement scholars agreed that it was time to reintroduce social psychological variables into social movement studies (Gamson et al., 1982; Snow et al., 1986). Both structural and organizational theories have contributed significantly to the understanding of the successes or failures of social movements and continue to do so (McAdam, McCarthy, \& Zald, 1996; Noakes \& Johnston, 2005), albeit typically with acknowledgment that social psychology contributes an essential element toward understanding social movement processes and development. Today social psychology, addressed through the perspective of framing, continues to be a relevant and common means to explore the construction of meaning in social movement research.

Social movement framing. Beginning in the mid-1980s, framing emerged as a way to explain less rational and practical factors in movement outcomes, as well as a way to understand the interpretive meaning assigned to movement activities by participants (Snow \& Benford, 1988; Snow et al., 1986). When looking at social movement activities through the lens of framing one investigates how information is 
articulated and the shared meanings that particular articulation garners. The framing perspective takes into account that meanings are created in a discursive process between social movement participants and other parties (Snow et al., 2004). Some of the first theorists to bridge these ideas voiced the need for a framing perspective succinctly:

Perhaps the occurrence, intensity, and duration of protest cycles are not just a function of opportunity structures, regime responses, and the like, but are also due to the presence or absence of a potent innovative master frame ${ }^{1}$ and/or the differential ability of [social movement organizations] to successfully exploit and elaborate the anchoring frame to its fullest (Snow et al., 1986, p. 477).

Framing operates as a means for social movements to create shared meaning by presenting ideas in a particular light and for participants and bystanders to interpret those ideas using and altering the frames already in place in their minds. Social movement scholars credit noted sociologist Goffman as formulating framing as a way to process and organize information. Goffman articulated frames as having the ability to "[render] what would otherwise be a meaningless aspect of the scene into something that is meaningful" by enabling someone to "locate, perceive, identify, and label a seemingly infinite number of concrete occurrences defined in its terms" (1974, p. 21).

It did not take long for scholars of social movements to appreciate the power of framing. Two scholars, Gitlin and Gamson, were among the first to shift social

\footnotetext{
${ }^{1}$ A master frame is grand-scale frame, one that bridges organizations, movements, time, and potentially geography as well (Snow \& Benford, 1992). A good example is the frame of civil rights that has been applied to both the African-American equality movement and the Freedom to Marry movement for gay, lesbian, and transgender couples.
} 
movement studies from a focus on structure, organization, and process to interpretation and meaning development in collective action, using framing as the central theory. Gitlin (1980) used frames to analyze the way the news media shaped public reception of the 1965 Students for a Democratic Society protests and activities and how the movement responded to that coverage. He found that media coverage worked within a system of mostly subconscious framing. These media frames influenced the successes and failures of the movement because they shaped what the movement meant to people by becoming the dominant narrative about that movement (Gitlin, 1980).

In contrast to Gitlin's emphasis on frames constructed by the media, the next researchers to use framing analysis on social movements, Gamson, Fireman, and Rytina (1982), focused on people's internal interpretive processes. In their experiments, participants who initially held a frame that assumed the legitimacy of authority broke that frame and reconstructed it to one of unjust treatment. The transition occurred when authority violated moral norms by asking people to publicly carry out an action that they found unethical. The study illuminated how this reframing process serves as a first step toward collective action and how participants' interpretive processes were essential (Gamson et al., 1982).

From these initial forays into framing analysis of social movements, research has evolved in two complementary directions: a focus on cognitive frames, the schema existing in the mind of the receiver such as the injustice frame identified as the basis of collective action by Gamson et al.; and an emphasis on message frames 
generated by the sender, such as those identified by Gitlin in news coverage of a social movement. Cognitive framing studies tend to focus on understanding how changes in people's internal perceptions of issues influence movement outcomes, while message framing studies look at how the framing of movement texts influence movement outcomes (Johnston, 1995). Clearly, the two are closely linked; in fact cognitive and message framing processes should not be assumed to work independently of each other since framing is a dialogic process in which both the mental processes of potential constituents and message composition by movement actors coexist and continuously interact (Benford \& Snow, 2000; Snow \& Benford, 1992; Snow et al., 1986). Social movement research in each camp typically acknowledges or incorporates elements of the other and concedes that the ability and willingness of message recipients to reframe their experiences determines the success or failure of movement outcomes as much as the composition of movement texts.

Message framing studies in social movements have developed beyond Gitlin's work. As mentioned above, emphasis is typically on communication between the movement actors themselves. Message framing studies, as articulated by McAdam, should focus on: "conscious strategic efforts by groups of people to fashion shared understandings of the world and of themselves that legitimate and motivate collective action" (1996, p. 6). Ultimately, using the framing perspective in scholarship increases understanding of how movement actors have contributed to successful collective action by developing shared identity and inspiring 
mobilization, thereby enabling a movement to achieve its goals (Haydu, 1999; Klandermans, 1984; Snow \& Benford, 1988; Snow et al., 1986).

The work of two researchers forms the foundation of studies in message framing: Robert Benford and David Snow. From 1986 to 1992, they formulated a number of concepts that have subsequently played a large role as variables in area scholarship. Four of those concepts and their elaborations directly informed this work: collective action frames, frame resonance, competing frames, and counter frames. Benford and Snow's conceptions of collective action frames significantly diverge from communication framing studies. Unlike the focus of most frame analysis that centers on identifying meaning and how that meaning shapes understanding through the construction of a text, these framing tools instead focus on the purpose of the communication. A statement analyzed from this perspective is seen as performing a specific task that helps to contribute to collective action. A statement that performs its task well advances the goals of the communication as well as the outcomes of the social movement as a whole.

Collective action frames. Benford and Snow $(1988,1992)$, starting with Goffman's (1974) conceptions of cognitive framing and deriving support for their ideas from a number of ethnographic studies of social movements, elaborated the types of frames which, when used together in messages conveyed by social movements, can inspire, motivate, and resonate with potential constituents. This set of frames, known as collective action frames, includes diagnostic, prognostic, and motivational framing tasks (Snow \& Benford, 1988, 1992). 
As part of their core framing tasks, diagnostic frames identify the problem and attribute blame to an entity. A diagnosis in the climate change discourse might include discussion of carbon pollution as the source of the problem and assign blame to national leadership and consumers. Prognostic frames identify the solution and convey a plan of action; responsibility is assigned for carrying out that action. Regarding climate change, a prognosis might include a suggestion to decrease use of fossil fuels and increase reliance on renewable energy resources, including specific steps people can take to do so. Motivational frames provide a call to action using vocabularies of motive (see Mills, 1940) (Benford \& Snow, 2000; Noakes \& Johnston, 2005; Snow \& Benford, 1988, 1992). The motivational task in climate change might be framed as a description of the bleak future we could face if we do not act now combined with the assertion that action will have an impact on the problem. The first two tasks, providing diagnoses and prognoses, enable people to come to agreement about an issue; the third task, providing motivation, is necessary to create engagement in the issue through action (Snow \& Benford, 1988). The concept of collective action frames also includes the dialogic process of interaction between the core framing tasks as presented in a movement's discursive practices (texts such as speeches, conversations, videos, etc.) and those creating and receiving those frames, its agents and potential constituents. It is this dialogic process that creates collective meaning and identity (Benford \& Snow, 2000).

The core framing tasks of collective action frames have been studied extensively in social movement research, typically with qualitative content analyses 
and/or observation. Numerous case studies have shown the myriad ways core framing tasks have been utilized in movement messages, illuminating social movement dynamics. For example, a comparative case study carried out through inductive analysis of interviews, observations, and texts identified the diagnostic, prognostic, and motivational frames in three faith-based community development organizations. Results indicated that the organizations aligned their goals with those of funding institutions, while each organization utilized different problem definitions (diagnostic frames) to meet those goals (Fitzgerald, 2009). Many other studies distinguish the charge that these frames carry out for the movement. For example, a content analysis on communication produced by an anti-biotechnology organization identified the predominant diagnostic theme as a violation of human rights and the predominant prognostic theme as restoration of those rights (Zschau, Adams, \& Shriver, 2012).

However, research has not established whether these core framing tasks affect the change in cognition for which they are named. Benford (1997) noted that empirical work had failed to successfully investigate whether collective action frames affect mobilization; scholars have continued to call out this oversight (Benford \& Snow, 2000; Johnston, 2005; Scheufele, 1999). However, given their repeated presence in successful movement messages, social movement scholars assumed that they play an essential role. Theoretical and empirical work posits that together collective action frames focus, make salient, and articulate ideas. They help redefine something that although previously seen as acceptable is now understood 
to be unjust or immoral and in need of correction (Gamson et al., 1982; Snow \& Benford, 1988, 1992; Snow et al., 1986). They weave together events and experiences into a meaningfully interconnected reality, allowing recipients to interpret information in a new way (Snow \& Benford, 1992). Collective action frames have a distinct purpose of not only providing meaning, but also creating action that challenges existing power structures and the understanding of reality established by those in power (Snow et al., 2004). In addition, they are dynamic: "The flow of events - biographical, local, national, and international - have a way of intruding into our realities and forcing us either to incorporate them into our current understandings or modify those understandings accordingly" (Snow et al., 2004, p. 393).

Frame resonance. Although creating message frames by using the combination of diagnostic, prognostic, and motivational tasks may sound simple and prescriptive, the effort is not complete without including the role of cognitive frames, the schema existing in the mind of the receiver. As discussed earlier, framing can be understood as an interaction between those composing messages using message framing, and those receiving messages where messages interact with their cognitive frames. Benford and Snow acknowledge the importance of this interaction with their conceptualization of what they call resonance.

According to Benford and Snow (1988; 2000), movement message framing has to align with people's cognitive frames and the broader culture in which we live in order to succeed. When "framing efforts strike a responsive chord or resonate 
within the targets of mobilization," it is referred to as frame resonance (Snow \& Benford, 1988, p. 198). Social movement organizations have to be aware not only of the frames they are creating in their messages but also how those frames mesh with the schema that potential participants have developed internally and the culture they live within externally.

Frame resonance requires both salience and credibility; these are the two components of resonance. There are three factors crucial in creating salience, or prominence in a person's consciousness, of a frame or set of frames. First, movement frames have to match the lived experiences of recipients, known as experiential commensurability; second, the effect of the frames depends on how central the issues addressed are to the lives of the recipients; and third, the message must have narrative fidelity, meaning its frames resonate with existing cultural narratives (Benford \& Snow, 2000; Snow \& Benford, 1988). In addition, in order to resonate, frames put forth by social movements must feel credible to the recipients. First, the claims need empirical credibility, meaning they have to fit with world events and commonly accepted knowledge. Second, those delivering the frames must be perceived to be believable, and finally, the messages being touted by movements must be consistent with the movement organization's actions, stated beliefs, and public face (Benford \& Snow, 2000; Snow \& Benford, 1988).

A study of the 1989 Chinese Democracy movement serves as a good illustration of the power of frame resonance. Students initiating the movement had to delicately balance their calls for change while still couching their messages in 
party-friendly terms in order to avoid immediate (and dangerous) backlash from the state. At the same time, they had to deliver a message that would ring true for the experiences of Chinese citizens in order to engage more people to act. They were able to do this by calling on traditional and Communist values and narratives that effectively pointed out the frequent grievances people were experiencing first-hand. In addition, they ensured their public actions matched their stated framings, achieving consistency in contrast with the state, which was reflecting inconsistency. In this way, the organizers achieved frame resonance and garnered the strongest and longest movement in Chinese Communist history despite profound structural and organizational limitations (Zuo \& Benford, 1995).

An additional element of resonance that I would like to attend to is the shaping of messages to be either rationally oriented or emotionally oriented. In the earlier discussion of the interaction between cognitive and message frames, most of the aspects of the viewpoints addressed in that discussion are enfolded into Benford and Snow's definition of resonance. For example, ELM's attention to life relevance is reflected in Benford and Snow's centrality and experiential commensurability and Kahneman's attention to likeableness and credibility is reflected in Benford and Snow's speaker credibility. However, Benford and Snow's conceptualization of resonance overlooks the role of rationally and emotionally oriented messages, an important piece to address since the way a message is presented can have significant influence on its ability to strike a "responsive chord." 
Competing frames and counter frames. Any time a potential constituent encounters framed messages put forth by social movement actors, she also undoubtedly encounters framed messages coming from elites, such as the media, the state, corporations, or any other entity that is part of the hegemonic structure in society. In addition, she may experience framed messages from other movements or organizations within the same movement (Benford \& Snow, 2000). Since social movement framing activities do not occur in a void, it is therefore worth defining two additional terms, competing frames and counter frames.

Frame competitions naturally occur because there are always multiple communicators present in society. Someone receiving one message will receive other messages with frames that may support, contradict, extend, or redefine the frames in that original message. Each frame competes for the attention of the recipient. In addition, those who compose messages often respond to competing frames already present in the culture, choosing to absorb, co-opt, contradict, or tread carefully around them (Noakes \& Johnston, 2005).

Occasionally, movement actors find competing frames within the same movement organization or within a coalition of organizations joining together for a limited duration. When this happens, organizations have to find innovative ways to effectively marry the frames or risk schism (Benford, 1993). This was the case for the Million Mom March and Code Pink protests in 2000 and 2007, respectively. The two movement organizations used message frames emphasizing women's biological and psychological differences from men, a maternal frame, as well as an equality 
frame stressing sameness with men. In both cases, organizers were able to successfully bridge the two frames with a third frame, the feminine-expressive frame. This frame reclaimed maligned feminine imagery and stereotypes and used them in playful irony to appeal to women who relate to either frame. For example, a call to action for the Million Mom March teasingly invited moms to gas up their minivans (Goss \& Heaney, 2010).

Closely related to competing frames is the concept of counter frames. Counter frames are those that attempt to "rebut, undermine, or neutralize a person's or group's myths, versions of reality, or interpretive framework" (Benford, 1987, p. 75, as cited in Benford \& Hunt, 2003, p. 161). These are competing frames that are specifically composed to contradict a particular frame, and they are usually put forth by a movement opponent. Counterframing can include movement responses to elite frames or elite responses to movement frames. In the aforementioned study of the 1989 Chinese Democracy movement, researchers found that one reason for the movement's longevity was that state messages countering the movement's actions were ineffective because they failed to mesh with people's real-life experiences (Zuo \& Benford, 1995).

Counter frames can also include movement or organization responses to frames advanced by other movements or organizations, or elite responses to other elite frames. For example, in Haydu's study of frames chosen by employers to counter union activities, he found that employers at times chose frames not because they countered union frames but because they reflected desirable frames emerging 
from other elite groups. Frames in the early 1900s were developing that established status hierarchies by elevating the work of the mind as opposed to manual labor. By demonizing union efforts that represented hand work, employers were able to associate themselves with the higher status group (Haydu, 1999). Counterframing sometimes involves responding to historical movement frames that if invoked today, would harm movement efforts. One frame used in the women's suffrage movement, that women's place was in the home (Hewitt \& McCammon, 2004), had to be countered in later women's movement activities once women no longer wanted to be confined to that arena (cf. Goss \& Heaney, 2010).

\section{The Current Study}

In order for social movements to achieve particular outcomes, they must persuasively articulate and amplify shared grievances (Snow \& Benford, 1992) as well as develop vocabularies of motive or reasoning that evokes action (Benford, 1993). Benford (1997) suggested that using case studies is the easiest way for scholars to study these aspects of social movements. In fact, the majority of research in this area has used case studies to look at frames retrospectively, and most has focused on successful movements (Benford, 1997). The problem with this method is that it is difficult to establish any kind of causal relationship, and results are skewed. Benford (1997) first called these issues to scholars' attention, saying, "We tend to work backward from successful mobilization to the framings activists proffered and then posit a casual linkage between the two" (p. 412).

This shortcoming has been identified by multiple scholars since then 
(Benford \& Snow, 2000; Johnston, 2005; Scheufele, 1999; Vicari, 2010). Scheufele (1999) specifically called for lab-based experimental designs to help establish framing effects on movement participation. Despite these pleas to incorporate empirical testing of collective action frames, little research has heeded that call. This study is intended to address that gap.

My primary interest is to understand how the framing of messages by social movements can affect a movement's impact by mobilizing participants. While shifting a person's perceptions about an issue to align with movement views is an important communication objective, mobilizing someone to play an active role is a necessary second step for movements to achieve their goals.

Mobilization involves attempts by a movement organization to inspire support through material or nonmaterial means (Klandermans, 1984). Mobilization can occur on a macro level, when broad changes (e.g. industrialization or war) shift power relations at a societal level. At the organizational, or meso level, mobilization tends to happen when those organizations that have more resources, including stronger and denser networks and the ability to create collective action, challenge the power structure. At the micro level, it is the shift in individuals' cognitions that create mobilization through collective interpretation of a problem, attribution of blame, and setting expectations for outcomes (Klandermans, 1984; Noakes \& Johnston, 2005; Snow et al., 2004). This means mobilization is both a response to cultural change and a cause of it (Snow et al., 2004).

This study focuses on both meso and micro mobilization processes: meso in 
terms of message construction by organizations and micro in terms of changes in cognition and interaction with existing cognitive frames. Meso mobilization can be achieved by attending to the core framing tasks of collective action frames: diagnostic, prognostic, and motivational framing; micro mobilization can be represented in the potential moderating effects of frame resonance, competing frames, and counter frames.

The audience of any social movement message consists of three categories in order of mobilization, from least likely to be mobilized to most: people who are not sympathizers, those who already sympathize with the movement's issue, and those who are already active in the movement (Klandermans, 2014). Within each category, of course, there are those who fall in the center and to each side, creating what we can imagine as a mobilization continuum extending from firmly opposed to passionate (see Figure 1). Both attitudes and actions determine where someone may fall on the mobilization continuum: a person's attitudes toward the movement's issue gauge the level of sympathy toward that issue and can be measured on an attitude scale; his actions measure the level of participation. Quantifying actual participation would be ideal, however given the scope of this study, measuring intention to act suffices. Study participants, therefore, can be placed along this continuum based on their self-reported attitudes about and intended actions on a social movement issue. A lower score, where attitudes are less sympathetic and actions are infrequent or nonexistent, places them toward the non-sympathizer end and a higher score toward the active end. 


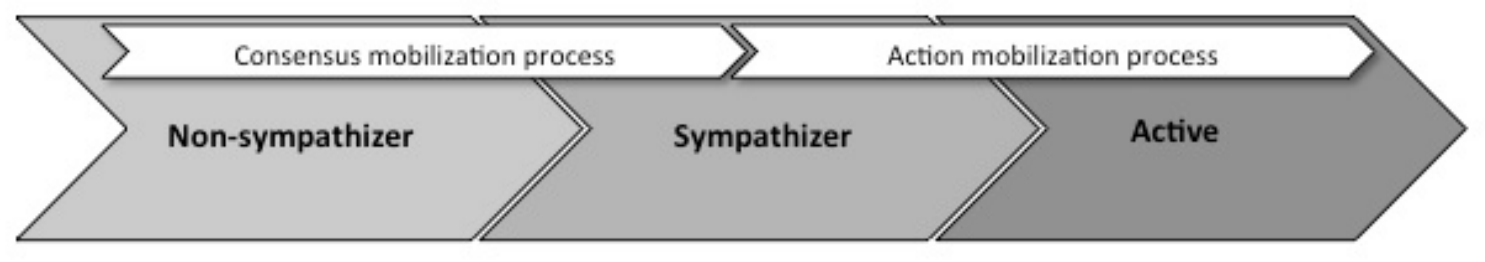

Figure 1. The mobilization continuum

Often those at the far left of the scale, the non-sympathizers, are rigid in their assessments of issues and unlikely to change positions (Klandermans, 2014; Maibach, Roser-Renouf, \& Leiserowitz, 2009; Scannell \& Gifford, 2013). Sometimes messages to this group result in recipients wanting to challenge what they are being told, known as counterarguing. When this takes place, messages often have opposite their intended effect, causing a boomerang in attitudes (Fishbein, Hall-Jamieson, Zimmer, von Haeften, \& Nabi, 2002; Moyer-Gusé, Jain, \& Chung, 2012). This type of result is likely one reason movement organizers rarely address messages to this group (Klandermans, 2014). Therefore, removing the non-sympathizers during analysis could provide more accurate results as to whether messages would have their intended effect on the typical target audience. On the other hand, those who fall not as far to the left on the continuum may not have rigid attitudes and can be thought of as potential sympathizers.

The three core tasks of collective action frames can be broken into two mobilization categories: diagnostic and prognostic framing that lead to consensus mobilization and motivational framing that leads to action mobilization (Klandermans, 1984, 2014). Consensus mobilization means creating a consensus in 
interpretation and understanding of a situation among constituents, in other words, creating a shared understanding of a social problem and how to address that problem. This is the process of moving a non-sympathizer or someone who is mildly sympathetic toward further sympathy. Action mobilization means transforming that consensus into action; shifting a sympathizer toward an active constituent (see Figure 1). This kind of mobilization means inspiring a supporter to join a protest, write a letter to the editor, talk about the issue with a neighbor, or any other variety of outcomes that require more than just a change in thought. Benford and Snow (1988) found that consensus mobilization does not automatically beget action mobilization; therefore motivational frames serve to provide the extra impetus. Based on this division, I chose to investigate whether inclusion of motivational frames in a climate change organization's persuasive messages did indeed increase action mobilization over messages that solely included diagnostic and prognostic framing tasks. By exposing one group to a treatment condition that includes motivational frames and another group to a treatment condition that excludes motivational frames, I make the following prediction:

H1: Mobilization levels, measured in terms of attitude and intention to act, for participants exposed to messages that include motivational frames will be significantly higher than mobilization levels for participants not exposed to motivational frames.

The dialogic process of framing suggests that I also investigate how the mental processes of potential constituents interact with message composition. Core 
framing tasks are enhanced when they resonate with the cognitive frames of recipients based on their salience and credibility (Snow \& Benford, 1988). Both salience and credibility can be measured using survey scales, and in addition, elements can be added into communication texts to increase the level of salience and the perception of credibility. "The extent to which a social movement's collective action frame succeeds in mobilizing people depends on whether it resonates with the targeted audiences" (Klandermans, 1984, p. 53). This leads to the prediction that resonance can have a direct impact on mobilization:

H2a: There will be a significant positive correlation between salience and mobilization such that as salience increases, mobilization levels will increase.

H2b: There will be a significant positive correlation between credibility and mobilization such that as credibility increases, mobilization levels will increase.

In addition, by exposing one group to a treatment condition that includes motivational frames and another group to a treatment condition that excludes motivational frames, I predict that resonance will serve as a moderating variable in the relationship between motivational frames and placement on the mobilization continuum:

H3: There will be an interaction effect between resonance and motivational frames such that resonance and mobilization will be more strongly 
associated with each other for participants exposed to motivational frames than for those not exposed to motivational frames.

Two additional variables that may influence the relationship between collective action frames and placement on the mobilization continuum are competing frames and counter frames. However, research has been inconclusive on the direction of influence (Benford \& Snow, 2000). Benford (1993) found that intermovement frame disputes were both beneficial and detrimental to Texas nuclear disarmament movement organizations. A study of the collective action frames used in the United States' women's suffrage movement found that counterframing opponents frames increased membership in suffrage organizations, yet the presence or absence of anti-suffrage organizations did not influence outcomes (Hewitt \& McCammon, 2004). Frequency of exposure to both competing and counter frames can be assessed through survey measures. Therefore, by measuring participants' exposure to competing and counter frames, I propose to investigate the direction of and strength of influence on mobilization levels with two research questions:

RQ1: What impact will exposure to competing frames have on mobilization levels?

RQ2: What impact will exposure to counter frames have on mobilization levels? 


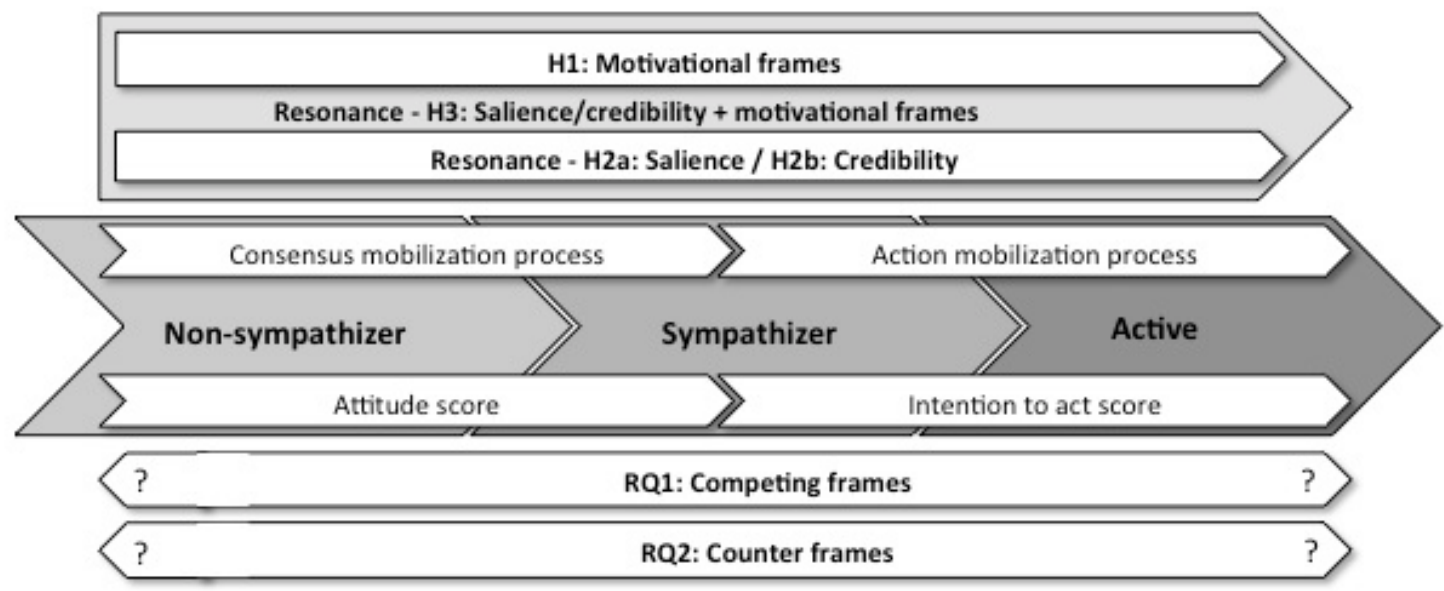

Figure 2. Hypotheses and research questions depicted on the mobilization continuum 


\section{Chapter 3: Methods}

\section{Participants}

I recruited participants from Amazon's Mechanical Turk, an online crowdsourcing site where people perform tasks, such as filling out social science surveys at their convenience, in order to earn minor monetary compensation ("Amazon mechanical turk welcome," n.d.). While a convenience sample, it is relatively diverse in comparison to the typical convenience samples many researchers access on the internet or college campuses (Buhrmester, Kwang, \& Gosling, 2011; Mason \& Suri, 2012). Any respondent that fully completed the survey was paid $\$ 0.50$. In order to qualify to respond to the survey, respondents had to confirm that they were at least 18 years of age, residents of the United States, and spoke English fluently.

Because this research required input from human subjects, the Institutional Review Board (IRB) performed an ethical review of the study procedures. The IRB is a formal university-appointed board that reviews, monitors, and approves research to assure that the rights and welfare of human subjects are protected. The IRB approved the original research procedure on February 27, 2015 and an amended procedure on March 18, 2015 (see Appendix A).

To ensure that my treatment conditions would have at least an 80 percent chance of finding a significant effect if one existed in the population, I conducted a power analysis using Harvard University's online power calculator (Shoenfeld, 2010 ) in order to determine an adequate sample size. I set my significance level at 
.05 with a view to being $95 \%$ confident the results did not occur by chance. I used the calculator by entering the means and standard deviations derived from scales that measured components of my dependent variable. Two scales used by Heath and Gifford (2006) measured behavioral intention to act on climate change $(M=3.33 ; S D$ $=0.38)$ and efficacy of cooperation $(M=3.23 ; S D=0.77)$. One scale used by Whitmarsh (2008) measured attitudes about climate change. Since Whitmarsh did not report the standard deviation of her scale, I used the standard deviation from a pilot test of the scale $(M=3.84 ; S D=0.67)$. By averaging these standard deviations, I was able to assume that the standard deviation of the dependent variable would be 0.71. Using this information, the power analysis indicated that in order to achieve statistical power of .80 for a two-tailed test with a .05 significance level, if the true change in the dependent variables is 0.13 units per one standard deviation change in the independent variable, I would need a minimum sample of 175 participants per condition. Since my experiment contained two conditions, the total number of participants should be at least 350 to achieve the desired power.

Respondents completed a survey and watched a short video in the Qualtrics survey platform. The survey was open for six days, in which 479 responses were collected. One duplicate respondent was removed. Those that did not complete the first 75\% of the survey $(n=71)$, and those that failed the experimental substantiations $(n=16)$ were removed. Additionally, anyone who spent far outside three standard deviations of time on any question $(n=9)$ was removed from the sample. The final number of participants was 382 . 
The participant sample was $51.5 \%$ female (1.1\% other). Caucasians represented $82.7 \%$ of the sample, with the next largest group being African American at 8.8\%; participants were allowed to mark more than one field. Age $(n=$ $372, M=39.21, S D=13.31$ ) was distributed along a bimodal curve, with peaks around $30(M o=30)$ and 60. More participants held a bachelor's degree $(n=143$, $38.1 \%)$ or at least some college $(n=94,25.1 \%)$ than any other level of education. More than $82 \%$ of respondents fell in the $\$ 0$ - $\$ 75,000$ income range, with the majority of that group $(n=143,37.9 \%)$ earning between $\$ 25,001$ - $\$ 50,000$. The sample skewed heavily Democratic, with more than twice as many respondents choosing that affiliation over any other $(n=178,47.5 \%)$; the next largest group chose no affiliation ( $n=79,21.1 \%)$ followed closely by Republican $(n=75,20 \%)$. See Appendix B for a complete description of demographic statistics.

\section{Procedure}

After providing informed consent (see Appendix C), participants completed a two-part survey. In the first part, participants responded to demographic questions and a scale on salience. Salience levels needed to be established before participants were primed by information in the rest of the procedure. After completing this portion of the survey, participants were randomly assigned to one of two video conditions described in detail below. Following the video, participants then returned to the survey to respond to questions substantiating the experimental manipulation, as well as scales on attitudes, intention to act, speaker credibility, and exposure to competing and counter frames. Lastly, participants answered a question 
on income. The entire process took approximately nine minutes to complete $(M=$ $8.80)$.

Videos. I chose to use a video as the vehicle for the experimental manipulation because video as a message medium is increasingly popular, with video-sharing sites such as YouTube.com growing exponentially in recent years (Cha, 2014). In addition, many studies have shown video to be superior to text in learning in terms of motivation and attention in online contexts (e.g. Choi \& Johnson, 2005). One study on news framing found that inclusion of visual imagery in news stories created interaction with both cognitive and affective elements of message processing. The authors concluded that images may have a powerful ability to activate preexisting cognitive frames (Domke, Perlmutter, \& Spratt, 2002).

For the video, participants were randomly assigned to one of two experimental conditions. The approximately three-minute videos were created from clips taken from the movie "Disruption," produced by 350.org ("Disruption," n.d.), used with permission from the organization. The organization created the movie in summer 2014 with intent to be shown throughout the world to encourage people to join the September 2014 People's Climate March. Clips taken from the movie contained messages about climate change but not the march, since those portions are no longer relevant given that the event has passed.

The edited videos contained staged clips of speakers such as relevant authors and representatives from media and climate change activist organizations. Speakers were featured from prerecorded footage from a meeting of the International Panel 
on Climate Change and organizing activities for the People's Climate March. The videos also showed scenic images of Earth, such as breaching humpback whales, and the stresses that the Earth is undergoing due to climate change, such as melting glaciers and extreme weather. Additional footage of people participating in protests was used. Either music or voice-overs played throughout the videos.

I constructed the videos to take into account the features of resonance as described above. The credibility component of resonance in this context consists of empirical credibility, frame consistency, and source credibility. Empirical credibility, meaning frames should fit with known world events, was addressed by using frames from the video that mesh with national or worldwide incidents that received national media coverage. Both versions of the video referred to recent extreme weather events that have been broadly covered in the national news. Frame consistency, the "congruency between [a social movement organization's] articulated beliefs, claims, and actions" (Benford \& Snow, 2000, p. 620), was addressed by choosing an organization that has demonstrated this consistency throughout its history.

To establish the narrative fidelity component of resonance, frames used in the videos were chosen to resonate with existing cultural narratives that have relevance to United States residents. Both versions of the video contained reference to the civil rights movement and the women's movement, major historical events, and weather, a very popular news topic ("Pew Research Center for the People \& the Press poll, Jan, 2014," 2014). For example, a message used in both versions of the 
video showed historical footage of the civil rights and women's movements and stated: "All the big social movements in history have had people in the streets; women's voting rights, civil rights movement, and even more recently on climate issues, our big successes have happened when people left their homes and went out in the streets."

Additionally, the videos used both cognitively oriented and affectively oriented arguments in order to increase the opportunities for resonance for people who respond to either type of message. Cognitively oriented messages used rational appeals to persuade viewers with facts and numbers. For example, a cognitively oriented message included in both versions of the video stated: "If we really want to bring about a limitation of temperature increase to no more than 2 degrees Celsius, there is then the need for an unprecedented level of international cooperation." Affectively oriented messages used emotional pleas to appeal to the feelings of viewers. For example, an affectively oriented message in both versions of the video stated: "I remember when the weather channel was this kind of like nice sleepy little station. Now it's like a horror show. The climate is being disrupted. That's not for next year or a thousand years from now, that's happening right now." Thus, resonance was enhanced through video composition.

While the two versions of the videos contained many similarities, they differed in one noteworthy way: version one of the video included six diagnostic frames and six prognostic frames but no motivational frames; version two included four of the same six diagnostic frames and five of the same six prognostic frames; 
additionally, at the end, the video included four motivational frames. The three diagnostic and prognostic frames were eliminated from the second version in order to ensure that the length of the two video conditions only differed by nine seconds.

Diagnostic frames present a cause of the problem or assign blame. One such frame presented in both videos states: "We've proven beyond a doubt that climate change is real, that the earth's temperature is warming, that that warming is predominantly caused by the burning of fossil fuels and other human activities, and that that additional warming poses a significant threat." Prognostic frames present a plan of action or a solution. An example of a prognostic frame found in both videos is: "Part of what we're doing is moving people from fossil fuels to the solutions and also presenting them with economic opportunities around the solutions." The content of the diagnostic and prognostic frames was carefully reviewed to ensure there were no calls to action included. Motivational frames provide a call to action, such as this frame presented only in the second version of the video: "It's our chance to show the immense power of people in solidarity." In this manner, I constructed the two treatments conditions for the experiment. See Appendix D for transcripts of and links to the videos.

Survey. The survey instrument measured five constructs: mobilization, in terms of attitude and intention to act scores, resonance, in terms of salience and credibility scores, exposure to competing frames, exposure to counter frames, and demographics. The survey contained six items on demographics. With the exception of a question on income, demographic items were posed first since placing these 
types of items early on Mechanical Turk surveys reduces attrition (Mason \& Suri, 2012).

The survey also included three items to substantiate the experimental manipulation. The first item asked participants to confirm whether they were able to view and understand the video; those that responded "No" were skipped to the end of the survey and subsequently removed from analysis. The second item asked participants to corroborate whether they viewed specific content in the video in order to provide an indication of whether they paid attention to the video. Lastly, toward the end of the survey, participants were asked whether they felt the video was more informational or motivational with a bipolar question. This question was used as a test for the strength of the experimental manipulation. See Appendix E for the complete survey instrument.

\section{Measures}

Mobilization. To measure climate change mobilization, participants responded to two variables that determined attitudes about climate change and intention to act on climate issues.

Attitudes. To measure attitudes on climate change, I used a 26-item scale created by Whitmarsh (2008), and removed two items referring to flooding since they were originally included specifically to measure the attitudes of flood victims. The scale included 14 items labeled attitudes that addressed awareness, perceived usefulness of acting to mitigate climate change, perceived relevance, and assignment of responsibility for action. An additional ten items labeled uncertainty addressed 
perceived threat. Negative items were reverse coded so that a higher score represented stronger concern about the threat of climate change and the perception that taking action is useful.

I pilot tested the 24-item scale ( $n=111, M=3.84, S D=0.67)$ and was able to reduce the length to eight items by performing orthogonal factor analysis with varimax rotation, while preserving good reliability. The initial output indicated four components with eigenvalues greater than 1 . However, based on recommendations from Costello and Osborne (2005), I used the scree plot as the definitive determinant, which showed a clear elbow at two components. This established my cut point at eigenvalues greater than 1.5: the first component was 11.104 and the second component was 1.631 . These two factors accounted for $53.06 \%$ of the common variance (Factor $1=42.27 \%$; Factor $2=6.79 \%$ ). Therefore, I restricted my loadings to two factors in SPSS (see Table 1).

Table 1

Rotated Component Matrix for 24-Item Attitude Scale

\begin{tabular}{lrc}
\hline Scale Items & \multicolumn{2}{c}{ Component } \\
& 1 & 2 \\
\hline $\begin{array}{l}\text { I tend to consider information about climate change to } \\
\text { be irrelevant to me }\end{array}$ & .411 & .562 \\
$\begin{array}{l}\text { If I come across information about climate change I } \\
\text { will tend to look at it }\end{array}$ & .465 & .206 \\
$\begin{array}{l}\text { Leaving the lights on in my home adds to climate } \\
\text { change }\end{array}$ & .398 & .344 \\
$\begin{array}{l}\text { Human activities have no significant impact on global } \\
\text { temperatures }\end{array}$ & .376 & .592 \\
$\begin{array}{l}\text { We can all do our bit to reduce the effects of climate } \\
\text { change }\end{array}$ & .253 & .621 \\
$\begin{array}{l}\text { Nothing I do makes any difference to climate change } \\
\text { nan }\end{array}$ & .160 & .761
\end{tabular}


one way or another

$\begin{array}{lll}\text { People should be made to reduce their energy } & .692 & .103\end{array}$ consumption if it reduces climate change

$\begin{array}{lll}\text { Radical changes to society are needed to tackle climate } & .779 & .189\end{array}$

change

There is no point in me doing anything about climate $\quad \begin{array}{lll}.192 & .815\end{array}$

change because no one else is

Nothing I do on a daily basis contributes to the $\quad .269 \quad .706$

problem of climate change

Industry and business should be doing more to tackle $\quad .626 \quad .375$

climate change

The government is not doing enough to tackle climate

change

It is already too late to do anything about climate $\quad .060 \quad .606$

change

I feel a moral duty to do something about climate $\quad .568 \quad .520$

change

Climate change is something that frightens me* $\quad .738 \quad .128$

The effects of climate change are likely to be $\quad .719 \quad .270$

catastrophic*

$\begin{array}{lll}\text { Claims that human activities are changing the climate } & .655 & .323\end{array}$

are exaggerated*

The evidence for climate change is unreliable* $\quad .599 \quad .511$

$\begin{array}{lll}\text { I do not believe climate change is a real problem* } & .508 & .545\end{array}$

The media is often too alarmist about issues like $\quad .592 \quad .470$

climate change*

It is too early to say whether climate change is really a $\quad .571 \quad .642$

problem*

There is too much conflicting evidence about climate $\quad \begin{array}{lll}\text { 59 } & .595\end{array}$

change to know whether it is actually happening*

I am uncertain about whether climate change is really $\quad .440 \quad .544$

happening*

$\begin{array}{lll}\text { Climate change is just a natural fluctuation in earth's } & .637 & .437\end{array}$

temperatures*

$\begin{array}{lll}\text { Percent of variance explained } & 28.36 & 24.70\end{array}$

*Items from the uncertainty portion of the scale

I proceeded to eliminate scale items, a few at a time, that did not load highly on either component and did not appear to have strong face validity, evaluating a newly generated rotated component matrix with each elimination round. The final 
iteration of the scale consisted of eight items that loaded highly on two factors: (1) uncertainty and assignment of responsibility for action and (2) usefulness of acting to mitigate climate change (see Table 2). Cronbach's alpha of the 8-item scale on the pilot test data was .84 .

Table 2

Final Attitude Scale - Rotated Component Matrix for 8-Items

\begin{tabular}{lcc}
\hline Scale Items & \multicolumn{2}{c}{ Component } \\
& 1 & 2 \\
\hline $\begin{array}{l}\text { People should be made to reduce their energy } \\
\text { consumption if it reduces climate change }\end{array}$ & .792 & .116 \\
$\begin{array}{l}\text { Radical changes to society are needed to tackle climate } \\
\text { change }\end{array}$ & .783 & .270 \\
$\begin{array}{l}\text { Climate change is something that frightens me* } \\
\begin{array}{l}\text { The effects of climate change are likely to be } \\
\text { catastrophic* }\end{array}\end{array}$ & .770 & .215 \\
$\begin{array}{l}\text { Human activities have no significant impact on global } \\
\text { temperatures }\end{array}$ & .349 & .607 \\
$\begin{array}{l}\text { We can all do our bit to reduce the effects of climate } \\
\text { change }\end{array}$ & .190 & .703 \\
$\begin{array}{l}\text { There is no point in me doing anything about climate } \\
\text { change because no one else is }\end{array}$ & .156 & .839 \\
$\begin{array}{l}\text { Nothing I do on a daily basis contributes to the } \\
\text { problem of climate change }\end{array}$ & .225 & .792 \\
\hline $\begin{array}{l}\text { Percent of variance explained } \\
\text { *Items from the uncertainty portion of the scale }\end{array}$ & 31.98 & 30.55 \\
\hline
\end{tabular}

The revised scale retained six items from the attitude portion, addressing perceived usefulness of acting to mitigate climate change and two items from the uncertainty portion addressing perceived threat (an affective response). The scale utilized a 5-point Likert-type response format ranging from $1=$ Strongly Agree to $5=$ Strongly Disagree. Cronbach's alpha of the scale was .93. 
Intention to act. Two scales created by Heath and Gifford (2006) measured behavioral intention to act on climate change and self-efficacy of cooperation (a.k.a. collective efficacy). Two modifications were made to the scales: the words "global warming" were replaced with "climate change" throughout so that these scales used the same wording as the other survey scales; one item in the intention to act portion of the scale was changed from positive wording to negative to balance the number of positively- and negatively-valenced items. Both scales utilized a 5-point Likerttype response format ranging from 1 = Strongly Agree to 5 = Strongly Disagree .

Heath and Gifford found that including a measure of collective efficacy is an important part of measuring intention to act on climate change since climate change is often thought of as a distant and scattered problem in which it can be difficult to imagine individual efforts can have consequences. In their study, a belief in a positive collective outcome was a significant component of intention to act (Heath \& Gifford, 2006). The scale items are shown in Table 3. Cronbach's alpha of the scale was .93. 
Table 3

Behavioral Intention and Efficacy of Cooperation Scales

\begin{tabular}{lc}
\hline Scale Items & $\begin{array}{l}\text { Reverse } \\
\text { Coded }\end{array}$ \\
\hline $\begin{array}{l}\text { Behavioral Intention Scale } \\
\text { There are simple things that I can do that will have a meaningful } \\
\text { effect to alleviate the negative effects of climate change }\end{array}$ & $\mathrm{X}$ \\
I believe that little things I can do will make a difference to \\
alleviate the negative effects of climate change \\
Even if I try to do something about climate change, I doubt if it \\
will make any difference \\
$\begin{array}{l}\text { There is very little I can do to mitigate the negative effect of } \\
\text { climate change }\end{array}$ \\
$\begin{array}{l}\text { Efficacy of Cooperation Scale } \\
\text { I plan to take some actions to stop climate change } \\
\text { I personally do not intend to do much to stop climate change } \\
\text { I will make no effort to mitigate the negative effects of climate } \\
\text { change }\end{array}$ \\
$\begin{array}{l}\text { I intend to take concrete steps to do something to mitigate the } \\
\text { negative effects of climate change }\end{array}$ \\
\hline
\end{tabular}

The behavioral intention portion included four items shown in Table 3 . Cronbach's alpha of the scale was .91. The behavioral intention and efficacy measures were averaged together using SPSS to create a single measure of intention to act with a Cronbach's alpha of .95. Thus, two separate measures, attitude and intention to act, each provided information on mobilization levels of participants.

Resonance. To measure the resonance of the climate change issue, participants responded to two different variables because, "two sets of interacting factors account for variation in degree of frame resonance: credibility of the proffered frame and its relative salience" (Benford \& Snow, 2000, p. 619).

Source credibility. Source credibility was measured using the 12-item 
Leathers Personal Credibility Scale (Leathers, 1986). The scale is a 7-point bipolar measurement of a speaker's perceived characteristics, shown in Table 4. The scale includes three elements as described by Leathers: competence, trustworthiness, and dynamism as perceived by the receiver. Dynamism is an affective rating based on how successfully the communicator has projected a feeling of confidence. In this study, instead of asking for a response to an individual speaker, the survey item asked participants to respond to the presenters in the videos as a group. The Cronbach's alpha of the scale was .95 .

Table 4

Credibility Scale

\begin{tabular}{lc}
\hline Scale Items & Reverse Coded \\
\hline Competent : Incompetent & $\mathrm{X}$ \\
Qualified : Unqualified & $\mathrm{X}$ \\
Well-informed : Poorly informed & $\mathrm{X}$ \\
Intelligent : Unintelligent & $\mathrm{X}$ \\
Honest : Dishonest & $\mathrm{X}$ \\
Straightforward : Evasive & $\mathrm{X}$ \\
Trustworthy : Untrustworthy & $\mathrm{X}$ \\
Sincere : Insincere & $\mathrm{X}$ \\
Assertive : Unassertive & $\mathrm{X}$ \\
Bold : Timid & $\mathrm{X}$ \\
Forceful : Meek & $\mathrm{X}$ \\
Active : Inactive & $\mathrm{X}$ \\
\hline
\end{tabular}

Salience. Salience in terms of collective action framesmeans that the issues addressed have "centrality, experiential commensurability, and narrative fidelity" (Benford \& Snow, 2000, p. 621). Centrality was established through response to Leiserowitz's 9-item Risk Perception Index (2006). This scale was created to 
measure people's perceptions of climate change risk including the likelihood of personal, local, and global impacts on humans and nature, as well as the seriousness of those impacts. I modified the scale by replacing the words "global warming" with "climate change" throughout, and altered the response format from 4 points to 5 points to parallel the other scales used for this construct. Items are shown in Table 5. The responses ranged from $1=$ Very to $5=$ Not at all. In addition, I supplemented the scale with an additional question to address experiential commensurability, or alignment of the lived experiences of recipients. This was established by asking for a response to the statement: "I have personally experienced the effects of climate change" (Myers et al., 2013). The response option used a 5-point Likert-type format ranging from 1= Strongly Agree to $5=$ Strongly Disagree . Cronbach's alpha of the salience scale without and with the additional question was .94.

Table 5

Salience Scale

\begin{tabular}{lc}
\hline Scale Items & $\begin{array}{c}\text { Reverse } \\
\text { Coded }\end{array}$ \\
\hline Worldwide, many people's standard of living will decrease & $\mathrm{X}$ \\
Worldwide water shortages will occur & $\mathrm{X}$ \\
Increased rates of serious disease worldwide & $\mathrm{X}$ \\
My standard of living will decrease & $\mathrm{X}$ \\
Water shortages will occur where I live & $\mathrm{X}$ \\
My chance of getting a serious disease will increase & $\mathrm{X}$ \\
\hline
\end{tabular}

Competing frames. To measure participants' exposure to competing frames, those that support, extend, or redefine the presentation of the issue in the video, participants responded to a pilot-tested question regarding their encounters with 
prognoses regarding climate change that were different from those presented in the videos. The matrix item asked: "How frequently in the last three months have you heard or seen information about climate change that stated or implied:." Five statements followed, shown in Table 6. Answer choices included seven interval options that ranged from $1=$ Never to $7=$ Daily. The Cronbach's alpha of the competing frames scale was .82 .

Table 6

\section{Competing Frames Scale}

Scale Item

There's nothing we can do to fix climate change

Climate change is not a big enough problem to worry about

We need to learn to adapt to climate change

We need to develop technological solutions to climate change (e.g. geo-engineering) It's not up to individuals to help resolve climate change because others (e.g. businesses, organizations, or government) are taking care of it

Counter frames. To measure participants' exposure to counter frames, those that contradict the presentation of the issue in the videos, participants responded to a pilot-tested question regarding their encounters with diagnoses that were in direct conflict to those presented in the videos. The matrix item asked: "How frequently in the last three months have you heard or seen information about climate change that stated or implied:." Three statements are shown in Table 7. Answer choices included seven interval options that ranged from $1=$ Never to $7=$ Daily. The Cronbach's alpha of the counter frames scale was .94. 
Table 7

Counter Frames Scale

Scale Items

Climate change doesn't exist

Climate change is not a problem

Climate change is not caused by humans

\section{Analysis}

Statistical analyses were conducted using IBM's statistical software program SPSS 21. Hypothesis 1 suggested that exposure to the motivational framing task would result in higher mobilization levels than without the motivational frames. I employed an independent samples $t$-test to determine if there was a significant difference in means between the group exposed to motivational frames and the group not exposed to these frames. I administered the $t$-test on the entire sample on both the attitude scale and the intention to act scale. As previously planned, I then divided the respondents into two groups: non-sympathizers and a group I call prospectives, which incorporates both those who may be potential sympathizers as well as those who are already sympathizers. I chose to make this division based on studies cited above that support the claim that non-sympathizers are highly unlikely to change position and therefore do not represent a typical target audience for social movement activities. After making this division, I administered a second set of $t$-tests on the prospective group.

Hypothesis $2 \mathrm{a}$ and $2 \mathrm{~b}$ hypothesized that when the issue and messages resonated with participants through salience and source credibility, mobilization 
levels would be higher. I ran a correlation (see Table 8) on the entire sample using both mobilization measures, intention to act and attitudes, and both resonance measures, source credibility and salience. Hypothesis 3 posited that there would be a closer association between resonance and mobilization with inclusion of motivational framing tasks. I tested this hypothesis by employing multiple linear hierarchical regression analysis, using intention to act as my dependent variable and comparing the independent variables of the two video versions, salience, source credibility, and a combined salience and video variable.

Research question 1 investigated whether exposure to competing frames would affect mobilization, and research question 2 examined the impact of exposure to counter frames. I divided the sample into populations of high or low exposure based on median survey responses so that half the participants would fall in each group. Including the prior division of the sample into presence or absence of motivational frames, the sample then consisted of four groups. I compared the means of each group's mobilization level on the intention to act scale using an ANOVA. I repeated the ANOVA after removing those respondents that fell at the lowest end of the mobilization continuum in order to better reflect a typical target audience for a social movement. I set alpha levels for each of the above tests at $p=$ .05 a priori; hypotheses and research questions were two-tailed. 


\section{Chapter 4: Results}

Before proceeding with analysis, all scale items were reverse coded as necessary so that higher scores represented stronger concern about the threat of climate change, higher level of intention to act on climate change, higher level of salience, and higher perception of speaker credibility. Preliminary analyses of the scales found that most followed a fairly normal distribution curve. However, three of the measures showed skewed response patterns. The attitude scale, which measured attitudes toward climate change, skewed negatively $(-1.02)$, as did the source credibility scale (-1.2). Participants overall felt that climate change was something to be concerned about and that changes should be made to address it ( $M$ $=3.83, S D=0.97)$. Likewise, participants found the sources in the video to be highly credible $(M=5.74, S D=1.18)$, with a mode of 7 out of 7 , indicating a high level of trust. These scores imply that both measures could be showing a ceiling effect. A third measure, that of exposure to competing frames, was also skewed (1.07). The mode for both competing frames $(M=2.62, S D=1.25)$ and counter frames $(M=$ $2.83, S D=1.66)$ was $1(1=$ Never $)$, indicating that participants encountered few competing and counter frames over a three-month period.

Mobilization level, the dependent variable, was measured on both the attitude scale and the intention to act scale. The attitude scale measured attitudes toward climate change and the intention to act scale measured behavioral intention to act on climate change, including a measure of self-efficacy of cooperation. After reverse-coding the negatively scored items, a higher score on either scale implied 
stronger mobilization. As shown in Table 8, a Spearman's rho correlation, used due to the skewed nature of the attitude scale, revealed that there was a significant positive high correlation between attitude $(n=382, M=3.83, S D=0.97)$ and intention to act $(n=382, M=3.61, S D=1.0), r(380)=0.80, p<.01$.

Table 8

Spearman's RhoCorrelations within Mobilization Measures and within Resonance Measures

\begin{tabular}{llll}
\hline Construct & & Attitudes & Salience \\
\hline Mobilization & & & \\
$\quad$ Attitudes & & & \\
Intention to act & Correlation Coeff. & .802 & \\
& Sig. & .000 & \\
& $n$ & 382 & \\
Resonance & & & \\
Salience & & & \\
Source credibility & Correlation Coeff. & & .566 \\
& Sig. & .000 \\
& $n$ & & 381 \\
\hline
\end{tabular}

Since there were two scales that made up a different construct, resonance, I also ran a Spearman's rho correlation on these scales: source credibility and the Risk Perception Index combined with the experiential commensurability question, which together were used to measure salience. Spearman's rho was again used because the credibility scale was skewed. While not as highly correlated as the two mobilization measures, the test showed that there was a significant positive moderate relationship between source credibility $(n=381, \mathrm{M}=5.74, \mathrm{SD}=1.18)$ and salience $(n=382, M=3.62, S D=0.95), r(379)=0.57, p<.01$ (see Table 9). 
Before proceeding with statistical analysis, several scales needed to be split into categories. As previously discussed, I planned to run some of my tests on two groups: the complete sample of participants $(n=382)$, and then again on a smaller group that represented those who would be open to persuasion, who I call prospectives. Eliminating those who are likely to remain steadfast in their responses regardless of whether they are exposed to new information (Maibach et al., 2009) could provide more accurate data on whether the motivational frames were having an effect on participants' mobilization levels as a reflection of a typical target audience for a social movement. Therefore, I determined a split point on the mobilization scales, intention to act and attitude, at 3 and above and below 3. By keeping everyone who responded with a 3 or above on the 5-point scales I would remove those who responded "Disagree" or "Strongly Disagree" yet keep those who responded "Strongly Agree," “Agree," or "Neither Agree nor Disagree” for the specific tests I planned to run in this manner. Prospectives represented a majority; the prospective group for the attitude scale yielded $n=318,83 \%$ of the original sample, and the prospective group for the intention to act scale yielded $n=304$, $80 \%$ of the original sample.

In addition, in order to enable an ANOVA test on my research questions, I split the competing frames and counter frames scales into high exposure and low exposure categories based on their median scores. I dichotomized the results of the responses to the competing frames scale $(n=380, M=2.8, S D=1.25)$ based on the median score of 2.4 into high exposure $(n=202)$ and low exposure $(n=178)$ to 
competing frames. I divided the results of the responses to the counter frames scale into high exposure $(n=180)$ and low exposure $(n=201)$ to counter frames, based on the median score of $2.7(n=381, M=2.8, S D=1.7)$.

Since both gender and political party often have a relationship with variables relating to environmental issues, I thought it appropriate to investigate these two demographic items as a preliminary review of my data. Gender proved to have a significant association with intention to act. After removing the small number of "other" responses, a two-tailed independent samples $t$-test showed that intention to act was different for males $(n=181, M=3.45, S D=1.0)$ than females $(n=197, M=$ $3.76, S D=0.97), t(376)=-3.07, p=.002$. This means that females have a significantly higher intention to act than males.

Additionally, political party showed different responses to intention to act by party affiliation. A one-way ANOVA indicated significant differences in intention to act across four party affiliations $\left(F=22.51, d f=3 / 378, p=.000\right.$, eta $\left.^{2}=.15\right)$. Democrats $(n=182, M=3.96, S D=0.76)$ showed a higher intention to act than Libertarians $(n=27, M=3.76, S D=0.97)$, followed by other $(n=97, M=3.58, S D=$ 0.89). Republicans $(n=76, M=2.96, S D=1.17)$ returned the lowest score of the four groups.

Because my study contained an experimental manipulation, I included a manipulation check in the survey. The manipulation check asked participants to indicate whether they felt the video was more informational or motivational on a 7point bipolar scale. A two-tailed independent samples $t$-test disclosed that 
responses on the manipulation check to the video containing no motivational frames $(n=192, M=3.94, S D=1.95)$ showed a significant difference from the responses to the video that included motivational frames $(n=186, M=4.34, S D=1.95), t(376)=$ $2.05, p=.04$, with participants suggesting the video containing motivational frames was more motivational than the video that did not contain motivational frames. Therefore, participants overall were able to distinguish the different intentions of the videos.

H1. Hypothesis 1 compared responses to the two versions of the video, one of which included motivational frames and one of which did not. A two-tailed independent samples $t$-test revealed that responses on the attitude scale to the video containing no motivational frames $(n=194, M=3.83, S D=0.07)$ did not show a significant difference from the responses to the video that included motivational frames $(n=188, M=3.83, S D=0.07), t(380)=.045, p=.96$. A second two-tailed independent samples $t$-test performed on the prospective group revealed similar results to the tests above. Responses on the attitude scale to the video containing no motivational frames $(n=160, M=4.18, S D=0.6)$ did not show a significant difference from the responses to the video that included motivational frames $(n=$ $158, M=4.17, S D=0.56), t(316)=.278, p=.78$.

The same procedure yielding almost identical results was performed on the intention to act scale. A two-tailed independent samples $t$-test revealed that responses on the combined intention to act scale to the video containing no motivational frames $(n=194, M=3.61, S D=0.07)$ did not show a significant 
difference from the responses to the video that included motivational frames ( $n=$ $188, M=3.61, S D=0.07), t(380)=.003, p=1.0$. After removing those who responded with less than a 3 on the scale, a two-tailed independent samples $t$-test revealed that responses on the intention to act scale to the video containing no motivational frames $(n=152, M=4.02, S D=0.05)$ did not show a significant difference from the responses to the video that included motivational frames $(n=$ $152, M=3.99, S D=0.53), t(302)=.313, p=.76$. Hypothesis 1 was not supported.

H2a and H2b. Hypotheses 2a and 2b investigated whether resonance would have an association with mobilization. Because the results from the source credibility scale and the attitude scale were skewed, I analyzed this data using a two-tailed Spearman's rho correlation. Analysis found that there was correlation between the two mobilization scales, attitude ( $n=382, M=3.83, S D=0.97)$ and combined intention to act ( $n=382, M=3.61, S D=1.0)$, and the two resonance scales, source credibility $(n=381, \mathrm{M}=5.74, \mathrm{SD}=1.18)$ and salience $(n=382, M=$ 3.62, $S D=0.95$ ). As shown in Table 9, all the correlations were statistically significant, ranging from moderate (.566) to high (.802). 
Table 9

Spearman's Rho Correlations among Mobilization and Resonance Measures

\begin{tabular}{llll}
\hline Construct & & \multicolumn{2}{c}{ Mobilization } \\
\hline Resonance & & Attitudes & Intention to act \\
Salience & Correlation Coeff. & .726 & .649 \\
& Sig. & .000 & .000 \\
Source credibility & $n$ & 382 & 382 \\
& Correlation Coeff. & .674 & .613 \\
& Sig. & .000 & .000 \\
& $n$ & 381 & 381 \\
\hline
\end{tabular}

Resonance had the biggest association with the attitude portion of mobilization. The correlation between attitude and salience shows that as attitude increased, salience increased. Similarly, the correlation between attitude and source credibility shows that as attitude increased, source credibility increased.

Resonance also had a significant association with intention to act, the other component of mobilization. As intention to act increased, salience and source credibility increased. Hypotheses $2 \mathrm{a}$ and $2 \mathrm{~b}$ are supported.

H3. Hypothesis 3 predicted that resonance and mobilization would be more strongly associated with each other for participants viewing the video that included motivational frames than for those who did not. I tested this hypothesis using multiple linear regression analysis in hierarchical blocks, with an interaction term combining the video version with salience (see Table 10). Regression is a way to predict the score of the dependent variable based on the scores of one or more independent variables. To answer my hypothesis, I chose to predict the scores of 
mobilization, focusing specifically on intention to act, using the independent variables of the video version and the two resonance measures, salience and credibility. I selected the intention to act component of mobilization instead of attitude as the predicted variable because participants' attitude scores already showed strong concern for climate change. After attitude change, the next step in the process would be inspiring participants to take action, moving them to the far right on the mobilization continuum. Therefore, scores for intention to act were the logical choice to predict in the regression. In addition, I assumed salience was the stronger predictor of the two components of resonance, given that overall participants found the speakers in the video to be highly credible. Since there was more variation in salience scores, those scores would be able to tell me more about the role of resonance than credibility would. Therefore, salience was the logical choice to create the interaction term with the video version. For the full results of the 6-model regression, see Table 10.

In the first and second models, I entered binary variables for gender and political party so that they would act as my control variables as the models progressed. Both being female and having Democratic party affiliation frequently have been positively associated with concern for climate change in past studies so those conditions served as the basis of comparison. Being male had a significant negative relationship with intention to act, $F(1,375)=9.40, R^{2}=.16 p=.002$. Those who were affiliated with the Libertarian Party and Republican Party and those who chose no affiliation also had a significant negative relationship with intention to act 
compared with Democrats, $F(5,371)=15.09, R^{2}=.17 p=.00$.

For model 3, I regressed intention to act on the video version as a binary variable $(0=$ no motivational frames; $1=$ motivational frames $)$. As expected based on my results from hypothesis 1 , the video version accounted for virtually none of the variance in the intention to act component of mobilization, resulting in an insignificant $t$-test and no additional variance explained. However, gender and political party maintained their significant influence, resulting in an overall significant ANOVA, $F(6,370)=12.54, R^{2}=.17 p=.00$.

For model 4, I added in the salience scores as a predictor of intention to act. From this point onward, gender and political party were no longer significant. With these demographic variables and video version held constant, salience significantly increased intention to act. This model accounted for just over $50 \%$ of the variance in intention to act, a $34 \%$ jump over the previous model, $F(7,369)=54.62, R^{2}=.51 p=$ .00 . The video version continued to produce an insignificant, albeit slightly larger, result in this model.

Resonance is comprised of both salience and source credibility, so I also added source credibility into the fifth model, which, with salience, accounted for $55.7 \%$ of the variance in intention to act, $F(8,368)=57.78, R^{2}=.557 p=.00$. The influence of salience remained significant while the influence of the video version remained insignificant.

Lastly, I added a variable that examined the salience $\mathrm{x}$ video interaction effect. This variable was added last to enable examination of the hypothesized 
interaction, the question of highest interest, while the influence of the other variables was held constant. Adding this variable to model 6 accounted for a little less than $1 \%$ of the variance in intention to act, with a total of $56.4 \%$ of variance explained, $F(9,367)=52.84, R^{2}=.564 p=.00$. Therefore, the interaction between the video and resonance significantly increased mobilization intention. It was not until the video containing motivational frames was combined with salience did the video have any positive impact, which supports hypothesis 3; resonance and mobilization are more strongly associated with each other for the video containing motivational frames. Interestingly, however, in this model, exposure to motivational frames significantly decreased intention to act with the other variables held constant. At the same time, salience and source credibility continued to play an important role in predicting intention to act. 
Table 10

Regression Models Predicting Mobilization Intention

Model Model Model Model Model Model

\begin{tabular}{clrrrrrr} 
Predictor & & 1 & 2 & 3 & 4 & 5 & 6 \\
\hline Gender (Male) & $b$ & -.312 & -.212 & -.070 & -.070 & -.005 & -.006 \\
& Beta & -.156 & -.106 & -.106 & -.035 & -.002 & -.003 \\
& Sig. & $\mathbf{. 0 0 2}$ & $\mathbf{. 0 2 7}$ & $\mathbf{. 0 2 7}$ & .347 & .946 & .937
\end{tabular}

Political Party ${ }^{\mathrm{a}}$

Libertarian $\quad b$

Beta

Sig.

Republican $b$

Beta

Sig.

No Affil. $\quad b$

Beta

Sig.

Other

$b$

Beta

Sig.

Video version $\quad b$

Beta

Sig.

Salience $\quad b$

Beta

Sig.

Source cred. $\quad b$

Beta

Sig.

Salience $\mathrm{x}$ video $\quad b$

Beta

Sig.

$R^{2}$

Change in $R^{2}$

Note: Significant values are bolded

a Reference is Democrat. $\begin{array}{lllll}-.684 & -.684 & -.122 & -.074 & -.025\end{array}$

$\begin{array}{lllll}-.174 & -.174 & -.031 & -.019 & -.006\end{array}$

$\begin{array}{lllll}.000 & .000 & .425 & .613 & .864\end{array}$

$\begin{array}{lllll}-.967 & -.967 & -.163 & -.113 & -.103\end{array}$

$\begin{array}{lllll}-.390 & -.390 & -.066 & -.045 & -.041\end{array}$

$\begin{array}{lllll}.000 & .000 & .136 & .280 & .320\end{array}$

$\begin{array}{lllll}-.394 & -.394 & -.127 & -.081 & -.086\end{array}$

$\begin{array}{lllll}-.160 & -.160 & -.052 & -.033 & -.035\end{array}$

$\begin{array}{lllll}.002 & .002 & .194 & .388 & .356\end{array}$

$\begin{array}{lllll}-.107 & -.107 & -.197 & -.095 & -.117\end{array}$

$\begin{array}{lllll}-.021 & -.021 & -.039 & -.019 & -.023\end{array}$

$\begin{array}{lllll}.664 & .665 & .299 & .599 & .516\end{array}$

$\begin{array}{llll}.002 & -.060 & -.008 & -.679\end{array}$

$\begin{array}{llll}.001 & -.030 & -.004 & -.341\end{array}$

$\begin{array}{llll}.983 & .409 & .910 \quad .013\end{array}$

$.706 \quad .542 \quad .450$

$.675 \quad .519 \quad .430$

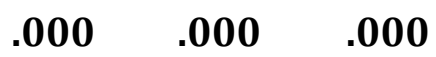

$.237 \quad .242$

$.281 \quad .287$

$.000 \quad .000$

.186

.364

.011

.564

$.169 \quad .169$

.509

.557

.007 
RQ1. Research question 1 looked at the effects of exposure to competing frames on mobilization. The 2 (level of exposure) x 2 (type of video) between groups ANOVA revealed that there was no significant interaction effect for mobilization intention between the two video conditions $\left(F=3.27, d f=3 / 376, p=.07\right.$, eta $\left.^{2}=.01\right)$. Moreover, the video with motivational frames in the low exposure group $(M=3.4$, $S D=0.96$ ) did not differ significantly from the video with motivational frames in the high exposure group $(M=3.8, S D=1.03)$. However, there was a main effect of exposure to competing frames on mobilization intention $(F=4.13, d f=3 / 376, p=$ $\left..04, e t a^{2}=.01\right)$. The low exposure group $(M=3.5, S D=0.96)$ had a significantly lower intention to act than the high exposure group $(M=3.7, S D=1.03)$.

As in the analysis for hypothesis one comparing the video version with the mobilization scales, a second set of tests was performed on the prospective group with high exposure $(n=167)$ and low exposure $(n=135)$ to competing frames. Once again, no interaction effect was found $\left(F=3.68, d f=3 / 298, p=.06\right.$, eta $\left.a^{2}=.03\right)$, where the video with motivational frames in the low exposure group $(M=3.84, S D=$ 0.59) did not differ from the video with motivational frames in the high exposure group $(M=4.13, S D=0.67)$. However, as above, a main effect between exposure to competing frames and mobilization intention was significant $(F=4.37, d f=3 / 298, p$ $=.04, e t a^{2}=.03$ ). Therefore, in answer to research question 1 , regardless of where a participant fell on the mobilization scale and regardless of which video was seen, higher exposure to frames that extend, support, or redefine the way climate change was presented in the video was related to increased intention to act. 
RQ2. Research question two looked at the effects of exposure to counter frames on mobilization. Similar to the results of the ANOVA above, the 2 (level of exposure) x 2 (type of video) between groups ANOVA revealed that there was no significant interaction effect for the intention to act portion of the mobilization construct $\left(F=3.63, d f=3 / 377, p=.06\right.$, eta $\left.{ }^{2}=.02\right)$. The video with motivational frames in the low exposure group $(M=3.45, S D=0.95)$ did not differ significantly from the video with motivational frames in the high exposure group $(M=3.82, S D=$ 1.07). Additionally, no main effect was found between exposure to counter frames and intention to act $\left(F=2.92, d f=3 / 377, p=.09\right.$, eta $\left.^{2}=.02\right)$.

As above, a second set of tests was performed on the prospective group with high exposure $(n=145)$ and low exposure $(n=158)$ to competing frames. The results showed a significant interaction effect between the video type and counter frame exposure for intention to act $\left(F=6.29, d f=3 / 299, p=.01\right.$, eta $\left.{ }^{2}=.04\right)$, as well as a main effect between counter frames and intention to act $(F=4.83, d f=3 / 299, p$ $=.03$, $\left.e t a^{2}=.04\right)$. The video with motivational frames in the low exposure group $(M$ $=3.84, S D=0.6$ ) had a significantly lower impact on intention to act than the video with motivational frames in the high exposure group $(M=4.18, S D=0.64)$. In fact, the low exposure motivational frames group had a lower intention to act than the low exposure group who had seen the video without motivational frames $(M=4.03$, $S D=0.63$; see Figure 2). Therefore, in answer to research question 2 , when the least mobilized participants were removed, higher exposure to counter frames was related to increased intention to act both on its own and in combination with the 
video containing motivational frames. However, when all participants were considered, exposure to counter frames did not have an impact on intention to act.

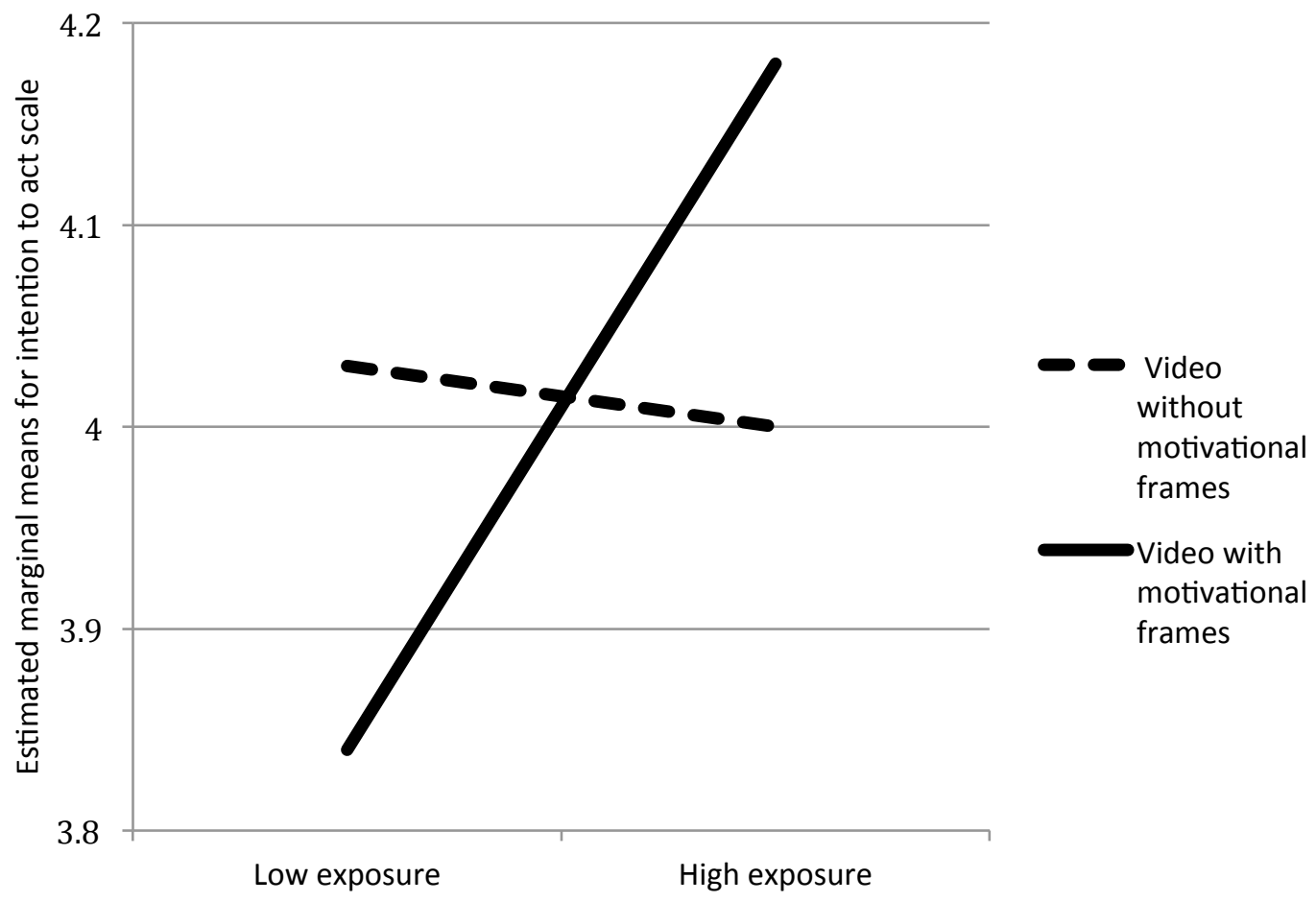

Figure 3. Estimated marginal means for prospectives on intention to act scale for low and high exposure to counter frames by video version 


\section{Chapter 5: Discussion}

The purpose of this study was to investigate how social movement actors can shape their messages to engage audiences and what inclines individuals to respond. I sought to understand how collective action frames can influence mobilization of constituents and potential constituents. Motivational frames were the primary target of my study due to their potential to inspire active involvement in issues and their relative lack of predictive study. Acknowledging the dialogic and dynamic nature of communication, I also investigated the role of resonance to account for the influence of the audience, as well as competing and counter frames, to account for the impact of other messages in the environment.

\section{Study Results}

Motivational frames. Motivational frames produced a variety of results under a range of conditions (see Figure 4). The first hypothesis suggested that those who watched the video including motivational frames would respond with higher scores on the mobilization scales than those who watched the video that did not include motivational frames. In fact, the results showed virtually no difference in response between the two video conditions. Hypothesis 3 further delved into the role of motivational frames in the video. For this hypothesis, I predicted there would be an interaction between resonance and motivational frames that would increase response to motivational frames. While controlling for salience and its interaction, motivational frames decreased mobilization. However, for those who found the video salient, motivational frames significantly increased mobilization. Additionally, 
my research questions once again looked to motivational frames to see if there would be an interaction effect between exposure to competing or counter frames and the video that affected mobilization. While exposure to counter frames did not interact with motivational frames for the whole sample, there were significant interaction effects for the prospective group; motivational frames increased mobilization for those who were prospectives.

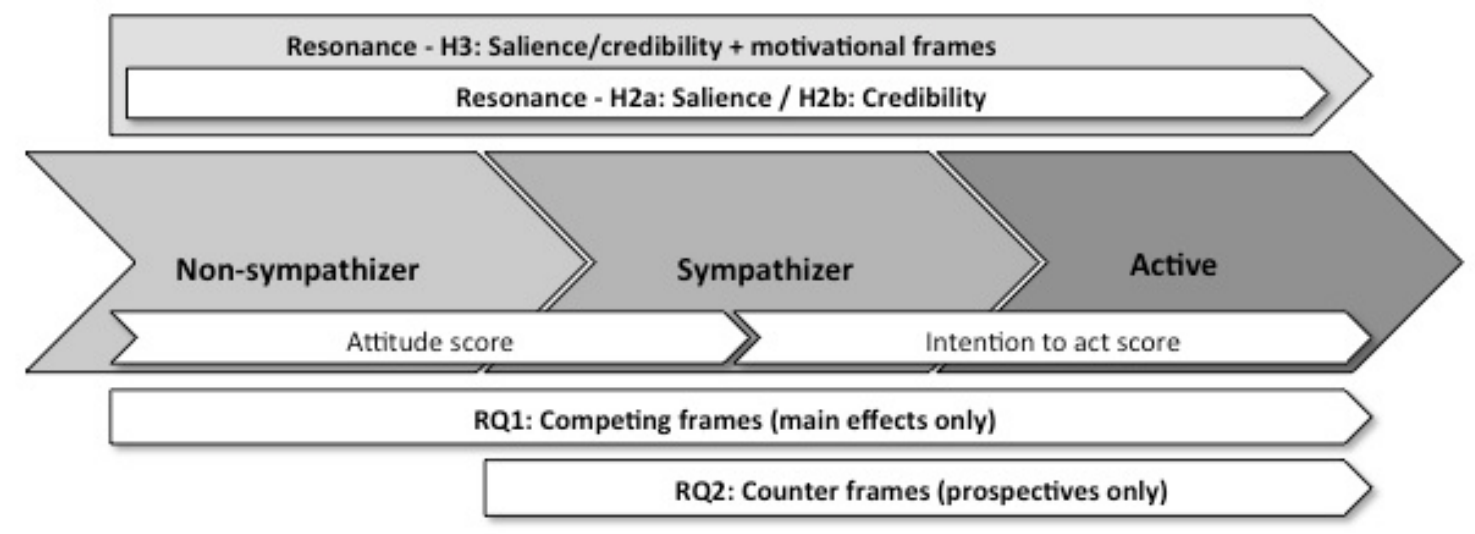

Figure 4. Results depicted on mobilization continuum

As discussed previously, the three core tasks of collective action frames can be broken into two mobilization categories: diagnostic and prognostic framing that lead to consensus mobilization and motivational framing that leads to action mobilization, the final impetus to get involved after attitudes have been shifted toward sympathy (Klandermans, 1984, 2014). However, the results of the primary hypothesis proposing an increase in mobilization due to exposure to motivational frames did not support a simple and direct effect. Results showed that for those participants for whom the issue of climate change was salient, motivational frames 
were important. Consensus mobilization, or creating a shared understanding of an issue, may have already happened for those experiencing a higher level of salience given their preexisting cognitive frames. If this were the case, they would be primed for action mobilization and perhaps ready to respond to motivational frames. This would indicate that if an issue is known to be highly salient to an audience, motivational frames become an important component of mobilization. On the other hand, if an issue is not salient, motivational frames will have little or possibly even negative impact on attitudes or intentions to act.

The possibility of the negative impact of motivational frames was illustrated in the regression analysis: while controlling for salience and its interaction, motivational frames decreased mobilization. I suggest that when salience is held constant, motivational frames could be triggering a boomerang effect. This test was run on the entire sample, so includes approximately $19 \%$ of participants who responded "Strongly Disagree" or "Disagree" to the attitude and intention to act scales. Counterarguing, and thus a boomerang, can take place when messages are perceived as weak (Fishbein \& Cappella, 2006; Fishbein et al., 2002). For participants that did not perceive climate change as a salient issue, a call to action could well be interpreted as a weak argument, since it does not define the problem, identify a target, propose any solutions, or outline a plan of action; it merely encourages the receiver to act. Therefore, the inclusion of motivational frames may have decreased concern about and intention to act on climate change when the influence of salience was removed. This indicates that it is important to target 
messages that include motivational frames to those for whom the issue at hand is salient, perhaps minimizing motivational frames when that audience cannot be precisely targeted.

Counter frames, those that contradict the framing of the issue presented in the video, contributed to prospectives' intention to act when they saw motivational frames in the video for those with high exposure. A sympathizer to the issue at hand would by definition disagree with counter frames. Motivational frames may have triggered a response to fight back against those oppositional frames among those who had higher exposure to counter frames, since exposure to counter frames would heighten awareness of antagonistic forces. If this were the case, when addressing an audience of sympathizers, it would be beneficial to directly respond to counter frames within messages to remind receivers of the challenges they face.

Interestingly, those who had low exposure to counter frames and saw the video with motivational frames scored lower on the intention to act scale than those who had high exposure to counter frames and saw the video without motivational frames (see Figure 3). Perhaps those who have seen few counter frames feel that there is plenty of support for the issue so taking action themselves is of lower importance. The free rider dilemma posits that if someone believes that her contribution will not have much impact and at the same time believes that there are enough others involved that the movement will be successful, she is disinclined to act (Klandermans, 1984). Klandermans suggests that since a free rider generally supports the issue at hand, it is still possible to engage her when it is necessary to 
involve a large percentage of people. He suggests personal and social reward motives, instead of collective reward, may be the path to success. The motivational frames used in the video appeal to collective good instead of personal reward (e.g. "It's our chance to show the immense power of people in solidarity"), thereby explaining the discrepancy in responses if the free rider dilemma is at play.

There are three possibilities as to why motivational frames may only serve their purpose well with the enhancing effect of salience or high exposure to counter frames. Motivational frames on their own may not have the strength to move people along the mobilization continuum without a significant amount of preparatory work from diagnostic and prognostic framing. In other words, diagnostic and prognostic frames may be the heavyweights in the collective action trio and motivational frames may provide the extra punch that works only when conditions are just right. It is difficult to parse out where the influence is coming from between the three types of frames within one experiment, but if, in fact, motivational frames do not have a strong connection with mobilization, that means persuasive messages should focus their weight on the other two types of frames with only occasional use of motivational frames.

The second possible explanation is that for those without prior salience or who were not already sympathizers, viewing a single three-minute video with motivational frames was not enough to move respondents to a new place on the mobilization continuum. It is well documented that shifts in attitudes and changes in willingness to act happen over a long time through multiple exposures to media 
(Meyer, 2009). It is this type of exposure that builds salience; additional exposure also increases the likelihood of encounters with counter frames. Researchers have found that climate change attitudes in particular can be a challenge to transform with a single message (Scannell \& Gifford, 2013).

A third possibility for the conditional influence of motivational frames is that the particular participant group that took part in my study have already been exposed to enough similar collective action frames so that we are seeing a ceiling effect. Over the past nine months, climate change has been heavily covered in the news and discussed at a policy level. Severe or unusual winter weather was experienced over a large portion of the United States during the first quarter of 2015; as discussed above, those who experience the perceived effects of climate change are more likely to believe it is a problem (Myers et al., 2013). In this case, either video version could trigger schema related to motivational frames to which participants may have recently been exposed. Additionally, a large portion of participants are Democrats, who in general are more likely to support climate change action (Maibach et al., 2009), and in fact, the ANOVA on political party confirmed that Democratic participants in this study have a stronger intention to act. This finding has been supported by past research (e.g. McCright \& Dunlap, 2011). Furthermore, participants' most commonplace response to both scales asking how frequently they had been exposed to competing and counter frames over the last three months was "never." This answer indicates that the collective action frames they have been seeing closely resemble the frames they saw in the 
video. Therefore, there may not have been much room for them to increase mobilization levels in response to the motivational frames in the video. It is likely that all three of these possibilities played a role in the limited influence of motivational frames revealed here.

Resonance. Salience, as discussed above, is just one component of resonance. By including resonance in my study, I was able to include participants' preexisting schema in the experiment. Resonance was attributed in a variety of ways, including incorporating into the video world events such as severe weather, cultural narratives such as the civil rights movement, use of messages from a consistent and credible organization, and inclusion of both cognitively and affectively oriented appeals. Additionally, two specific scales measured two components of resonance in participants: salience, discussed in part above, and source credibility.

Hypotheses $2 \mathrm{a}$ and $2 \mathrm{~b}$ proposed that higher levels of resonance would increase scores on the mobilization continuum. Self-reported resonance, in terms of both salience and source credibility, had a larger correlation with the attitude portion of mobilization compared to the intention to act measure, although the correlations between both resonance measures and intention to act were also significant. Given the previous discussion about the likely predisposition of participants, it is not surprising that resonance would have a strong relationship with the outcomes of mobilization. Participants in a sense were primed for the material in the video because they had likely already experienced messages that laid 
the schematic groundwork to be receptive to further messages. Based on this assumption, the importance of creating messages that resonate with an audience is confirmed with the results of these tests. Resonance could increase mobilization levels as well as create strength and longevity in social movements, according to findings from researchers such as Zuo and Benford (1995).

Of the two components of resonance that I measured, salience had a higher correlation than source credibility on both mobilization measures, although both were significant. This could mean that climate change is, in general, an issue that participants feel they have firsthand experience with, that the issue is central to their experience, and/or that it fits with their cultural narratives. In addition, source credibility has been shown to play a larger role for topics about which people are less knowledgeable or involved. According to the elaboration likelihood model, people rely on cues about the message source, such as source credibility, when they are not motivated to process the message or have little knowledge of the topic (Petty \& Cacioppo, 1986). In addition, people use source credibility cues to create mental shortcuts in System 1 thinking (Kahneman, 2013). Overall, participants in this study appear to have had experience with the topic, based on salience scores, and appear to be motivated to process information about climate change, based on attitude and intention to act scores, perhaps engaging in central route and System 2 processing. This would explain why source credibility would have a lower correlation with mobilization levels than salience. This finding indicates that for a fairly knowledgeable and engaged audience, more effort should be placed on 
creating messages that resonate with preexisting cognitive frames than on finding credible sources to deliver those messages.

Competing and counter frames. In acknowledgement of the dynamic nature of the communication environment, I also posed questions about participant exposure to frames other than those presented in the video. As discussed above, research question two examined whether exposure to counter frames would interact with the mobilization measure of intention to act, and results indicated significant interaction effects with the motivational frames in the video for the prospective group. However, when the full group was analyzed, both prospectives and non-sympathizers together, there were no significant interaction effects between the video and exposure to counter frames, nor were there main effects of exposure to counter frames on intention to act.

Results for the first research question, that regarding competing frames, differed from results for the query about counter frames. This question postulated whether those exposed to competing frames would have an effect on mobilization levels. Competing frames are those that support, extend, or redefine frames presented in the original message. When the full group was analyzed, both prospectives and non-sympathizers together, there were no significant interaction effects between the video and exposure to competing frames. However, main effects were found for high exposure to competing frames on intention to act with both the full group and the prospective group (see Figure 3).

Competing frames and counter frames may have different outcomes because 
competing frames present supporting information whereas counter frames present contradicting information. Competing frames may be inspiring action on climate change regardless of motivational frames because when more frames of any kind are present in the environment vying for attention, the issue will be more salient and likely spur more thought. The competing frames on climate change presented in my survey did not deny the existence of climate change or its anthropogenic causes, they instead presented different diagnoses (e.g. "There is nothing we can do to fix climate change") or prognoses (e.g. "It's not up to individuals to help resolve climate change because others (e.g. businesses, organizations, or government) are taking care of it"). In this way, competing frames may act to reinforce the idea that climate change is real and happening now, which could motivate action. The interaction effect for exposure to both competing and counter frames on the full group may not have been significant because these frames could also produce equivocation about who is responsible for action and whether action would be efficacious. In other words, weakening the influence of diagnostic and prognostic frames might weaken the influence of motivational frames.

\section{Limitations and Future Research}

This study has several limitations. The study used a convenience sample that, while more representative of the U.S. population than a student pool, is still not illustrative of the population as a whole. A clear example of this is in the heavily Democratic affiliation of my sample.

It is also noteworthy that the Levene's test of equality of error variances was 
significant in the ANOVA between political party and intention to act. Since an accurate ANOVA assumes equal variances, and my sample did not have equal variances, the results of this test should be considered to have some uncertainty even with a $p$ value of .000 .

Testing the strength of motivational frames on a single issue also has its limitations. Certain issues in the public dialogue have become so polarized that it can be difficult for people to be open to hearing another side. It is difficult to tell without replicating the test on other issues whether the potentially polarized attitudes about climate change altered the study outcomes. Ideally, the topic under study should have enough plasticity in attitudes in order to allow for change. If the issue were in fact highly polarized, that would affect the outcomes of the study in a way that would not necessarily be reflected if it were to be carried out on a different topic.

The scope of my study prevented comparisons of all three types of collective action frames and instead focused on the impact solely of motivational frames. Singling out one type of frame necessarily limits conclusions that can be made for collective action frames as a whole as well as the role and strength of diagnostic and prognostic frames. Additionally, the scope of this study prevented pilot testing the strength of the arguments in the collective action frames used in the videos. The outcomes of the study could be limited by diagnostic, prognostic, or motivational frames that did not have as robust argument potency as was intended by the researcher. If some statements were weaker than others, especially those containing 
motivational frames, that effect could confound the results of this study.

Another limitation is that a ceiling effect was observed in both the source credibility scale and the attitude scale. Not only were most participants ready to believe the speakers in the video, they were also concerned about the issue. Although these measures occurred after participants viewed the video, both source credibility and attitudes would be affected by beliefs and worldviews brought to the survey beforehand. For example, if someone were highly skeptical of anthropogenic climate change, he probably would not have found the speaker in the video to be credible when she says, “We've proven beyond a doubt that... that warming is predominantly caused by the burning of fossil fuels and other human activities." Likewise, if someone did not believe that climate change was real, she probably would not have shifted attitudes to the point of agreeing on the attitude scale that "Radical changes to society are needed to tackle climate change" after watching a three-minute video. Therefore, it is likely that a large number of participants came to the survey with pre-existing high levels on the mobilization continuum. This could mean that a number of participants in this study are ready to act on climate change and just need to be given the opportunity to do so. It also highlights the fact that it is difficult to isolate the influence of one message among many. Typically an accumulation of messages is what ultimately shifts someone from one category to another, not a single "magic bullet" message. This means measuring the effect of social movements is a challenging task: "The ways that movements make a difference are complex, veiled, and take far longer to manifest themselves than the 
news cycle that covers a single demonstration, or even a whole protest campaign" (Meyer, 2009, p. 418). Yet attempting to measure isolated influences is a necessary and important part of scientific inquiry. The contributions of my research on collective action frames will contribute to a body of work that, when taken together, can help inform social movement and communication researchers and practitioners.

To strengthen this body of work, future studies of collective action frames should be undertaken that test not just the relationship of motivational frames, but also of diagnostic and prognostic frames to other variables as well as to each other. A study with a broader scope could help to clarify the limited influence of motivational frames revealed here as well as elucidate the role and strength of diagnostic and prognostic frames. Ideally, a longitudinal study could measure the types of frames to which people are exposed over a period of time as well as the impact exposure has on their level of mobilization in order to understand the cumulative effect collective action frames may have.

I would also like to see studies that investigate a connection between motivational frames and collective efficacy. As theorized by Benford and Snow, collective action frames together contribute to a sense of collectivity, and motivational frames contribute to inspiration to act. Combined, I see the potential of motivational frames to be one of the keys to addressing the lack of collective efficacy that many people feel in confronting issues such as climate change.

Furthermore, I recommend that studies incorporating social movement issues attempt to find a topic that has not yet reached a high level of polarization in 
society. Lastly, further exploration of the role of competing and counter frames is needed in order to more precisely understand their influences on messaging and social movement actors.

\section{Conclusion}

The purpose of this study was to delve into the workings of collective action frames, the three strategic framing tools that social movements use to diagnose a problem, provide a prognosis, and inspire action. A better understanding of collective action frames provides important information on how social movements can affect public policy, political, economic, and social institutions, and the people who participate in them. Social movements are an integral part of shaping society, governments, and the global environment; understanding their strengths and how to build on those strengths can contribute to social change in meaningful ways.

This study focused on motivational frames, the tools that move a sympathizer, someone whose attitudes align with the movement, to an actor ready to collectively engage in creating change. This final step, moving people to action, is what enables movements to achieve outcomes such as, in the case of climate change, establishment and enforcement of new government policies, use of clean energy technology, divestment of funds from fossil fuels, and more.

The results of this study emphasize the importance of the dialogue between those creating messages and those receiving them in social movement communication, especially in the interaction between message frames and cognitive frames. Messages need to strike a responsive chord with target audiences, matching 
their lived experiences and resonating with existing cultural narratives. For those who resonate with the topic, the construction of the message itself may be more important than who is presenting the message. Additionally, messages need to acknowledge that other frames exist in the environment, some which support, some which extend or redefine, and some which contradict those presented in a social movement's message.

While motivational frames did not have a stand-alone impact on attitudes or intention to act, their interaction with resonance provides insight into one way in which messages can be enhanced to create inspiration to act. Resonance alone had a clear correlation with both intention to act and attitudes toward climate change, and additionally, once combined with the presence of motivational frames, had a direct influence on intention to act. Competing and counter frames both played a role in whether people planned to take action as well, emphasizing that we should not ignore the dynamic communication environment in which we all live. Lastly, the study results point to the importance of demographic variables such as gender and political party affiliation and the role they assume in engaging an active constituency.

Climate change organizations such as 350.org can use information from this study, keeping in mind its limitations, to help address what McKibben calls "a lack of will to act" ("Bill McKibben," 2012, p. 4). Using motivational frames combined with resonant ideas in organizational messages will address that lack. Heightening resonance could potentially address one of the barriers to participation in climate 
change mitigation, that the issue does not seem personally relevant. Increasing the number of motivational frames in messages could, theoretically, contribute to collective efficacy, addressing another barrier to action, that of fatalism. Targeting women and Democrats could contribute to increased responses to these messages and including reference to counter frames will help address the free rider problem. If organizations like 350.org can increase their effectiveness in meeting their goals, ideally that will serve to reduce the impacts of climate change now and into the future. The importance of this outcome cannot be understated.

By approaching the study of collective action frames in a predictive direction, this work contributes to the fields of social movement, communication, and framing studies. For almost 30 years, scholars have theorized and refined ideas about collective action frames, noting that many successful social movements use these frames and basing their findings retrospectively on the actions and outcomes of these movements. However, little research has been done to discover whether messages containing certain collective action frames, when compared with messages without these frames, are more effective in causing constituents and prospective constituents to engage in action. This study is the first step in understanding how collective action frames work from a predictive direction.

The findings of this study tell us that motivational frames in particular, when combined with resonant ideas, can influence intention to act. This illuminates how the social context that builds cognitive frames influences individuals' behaviors. We have seen how the social construction of meaning happens in the interaction 
between messages sent out by social movements, in the form of motivational frames, and cognitive frames, in the form of resonance. The meaning constructed in this case is that action matters. Articulating meaning through motivational frames creates shared meanings between movement leaders and participants in a dialogic process that can build the strength of movements and help them achieve specific outcomes. This study's discoveries support the theoretical foundations of collective action frames and the construction of meaning in social movements.

This study added to the large body of work on social movements, climate change, and communication. While further research is needed, the results of this experiment successfully showed that motivational frames contribute to mobilization, especially intention to act, under conditions of resonance and with the presence of counter frames. As social movements and climate change continue to profoundly shape our world in myriad and unknown ways, we will be better prepared to address those changes with the information provided here. Perhaps ideas that have evolved from this study will one day be used by the designer of a hallway poster or social media post that inspires a college sophomore to engage in an issue of vital importance, changing her life and the lives of those she touches, and ever so slightly changing the course of history. 


\section{References}

Amazon mechanical turk welcome. (n.d.). Retrieved November 25, 2014, from https://www.mturk.com/mturk/welcome

Basil, M., \& Witte, K. (2011). Health risk message design using the extended parallel process model. In H. Cho (Ed.), Health Communication Message Design: Theory and Practice (pp. 41-58). Thousand Oaks, CA: SAGE Publications, Inc.

Benford, R. D. (1993). Frame disputes within the nuclear disarmament movement. Social Forces, 71(3), 677-701.

Benford, R. D. (1997). An insider's critique of the social movement framing perspective. Sociological Inquiry, 67(4), 409-430. http://doi.org/10.1111/j.1475-682X.1997.tb00445.x

Benford, R. D., \& Hunt, S. (2003). Interactional dynamics in public problems marketplaces: Movements and the counterframing and reframing of public problems. In J. A. Holstein \& G. Miller (Eds.), Challenges and Choices: Constructionist Perspectives on Social Problems (pp. 153-182). New York, NY: Transaction Publishers.

Benford, R. D., \& Snow, D. A. (2000). Framing processes and social movements: An overview and assessment. Annual Review of Sociology, 26, 611-639.

Berry, H. L., Hogan, A., Owen, J., Rickwood, D., \& Fragar, L. (2011). Climate change and farmers' mental health: Risks and responses. Asia-Pacific Journal of Public Health, 23(2 suppl), 119S-132S. http://doi.org/10.1177/1010539510392556 
Bill McKibben: Actions speak louder than words. (2012). Bulletin of the Atomic Scientists, 68(2), 1-8. http://doi.org/10.1177/0096340212438383

Birk, T., \& Rasmussen, K. (2014). Migration from atolls as climate change adaptation: Current practices, barriers and options in Solomon Islands. Natural Resources Forum, 38(1), 1-13. http://doi.org/10.1111/1477-8947.12038

Blumer, H. (1969). The methodological position of symbolic interactionism. In $H$. Blumer, Symbolic interactionism: Perspective and method (pp. 1-60). Englewood Cliffs, NJ: Prentice Hall.

Buhrmester, M., Kwang, T., \& Gosling, S. D. (2011). Amazon's Mechanical Turk: A new source of inexpensive, yet high-quality, data? Perspectives on Psychological Science, 6(1), 3-5. http://doi.org/10.1177/1745691610393980

Cha, J. (2014). Usage of video sharing websites: Drivers and barriers. Telematics and Informatics, 31(1), 16-26. http://doi.org/10.1016/j.tele.2012.01.003

Choi, H. J., \& Johnson, S. D. (2005). The effect of context-based video instruction on learning and motivation in online courses. American Journal of Distance Education, 19(4), 215-227. http://doi.org/10.1207/s15389286ajde1904_3 Cook, J., Nuccitelli, D., Green, S. A., Richardson, M., Winkler, B., Painting, R., ... Skuce, A. (2013). Quantifying the consensus on anthropogenic global warming in the scientific literature. Environmental Research Letters, 8(2), 024024. http://doi.org/10.1088/1748-9326/8/2/024024 
Costello, A. B., \& Osborne, J. W. (2005). Best practices in exploratory factor analysis: Four recommendations for getting the most from your analysis. Practical Assessment, Research \& Evaluation, 10(7), 1-9.

D’Angelo, P. (2002). News framing as a multiparadigmatic research program: A response to Entman. Journal of Communication, 52(4), 870-888. http://doi.org/10.1111/j.1460-2466.2002.tb02578.x

Diani, M. (1992). The concept of social movement. The Sociological Review, 40(1), 125. http://doi.org/10.1111/j.1467-954X.1992.tb02943.x

Disruption: Climate. Change. (n.d.). Retrieved November 29, 2014, from http://watchdisruption.com

Domke, D., Perlmutter, D., \& Spratt, M. (2002). The primes of our times? An examination of the "power" of visual images. Journalism, 3(2), 131-159. http://doi.org/10.1177/146488490200300211

Duncan, S., \& Barrett, L. F. (2007). Affect is a form of cognition: A neurobiological analysis. Cognition and Emotion, 21(6), 1184-1211. http://doi.org/10.1080/02699930701437931

Edwards, K. (1990). The interplay of affect and cognition in attitude formation and change. Journal of Personality and Social Psychology, 59(2), 202-216. http://doi.org/http://dx.doi.org.proxy.lib.pdx.edu/10.1037/00223514.59.2.202

Egan, P. J., \& Mullin, M. (2014). Psychology: Local weather and climate concern. Nature Climate Change, 4(2), 89-90. http://doi.org/10.1038/nclimate2104 
Entman, R. M. (1993). Framing: Toward clarification of a fractured paradigm. Journal of Communication, 43(4), 51-58.

Fabrigar, L. R., \& Petty, R. E. (1999). The role of the affective and cognitive bases of attitudes in susceptibility to affectively and cognitively based persuasion. Personality and Social Psychology Bulletin, 25(3), 363-381. http://doi.org/10.1177/0146167299025003008

Fahlenbrach, K., Sivertsen, E., \& Werenskjold, R. (2014). Introduction: Media and protest movements. In Media and revolt: Strategies and performances from the 1960s to the present (pp. 1-16). New York, NY: Berghahn Books.

Fishbein, M., \& Cappella, J. N. (2006). The role of theory in developing effective health communications. Journal of Communication, 56, S1-S17. http://doi.org/10.1111/j.1460-2466.2006.00280.x

Fishbein, M., Hall-Jamieson, K., Zimmer, E., von Haeften, I., \& Nabi, R. (2002). Avoiding the boomerang: Testing the relative effectiveness of antidrug public service announcements before a national campaign. American Journal of Public Health, 92(2), 238-245. http://doi.org/10.2105/AJPH.92.2.238

Fitzgerald, S. T. (2009). Cooperative collective action: Framing faith-based community development. Mobilization, 14(2), 181-198.

Fossil free Europe. (n.d.). Retrieved November 24, 2014, from http://gofossilfree.org/europe

Gamson, W. A., Fireman, B., \& Rytina, S. (1982). Encounters with unjust authority. Homewood, IL: Dorsey Press. 
Gifford, R. (2011). The dragons of inaction: Psychological barriers that limit climate change mitigation and adaptation. American Psychologist, 66(4), 290-302. http://doi.org/10.1037/a0023566

Gitlin, T. (1980). The whole world is watching: Mass media in the making and unmaking of the new left. Berkeley, CA: University of California Press.

Giugni, M. G. (1998). Structure and culture in social movement theory. Sociological Forum, 13(2), 365-375. http://doi.org/10.1023/A:1022102218675

Goffman, E. (1974). Frame analysis: An essay on the organization of experience (Vol. ix). Cambridge, MA: Harvard University Press.

Goss, K. A., \& Heaney, M. T. (2010). Organizing women as women: Hybridity and grassroots collective action in the 21st century. Perspectives on Politics, $8(01)$, 27. http://doi.org/10.1017/S1537592709992659

Hansen, J., Sato, M., Kharecha, P., Beerling, D., Berner, R., Masson-Delmotte, V., ... Zachos, J. C. (2008). Target atmospheric C02: Where should humanity aim? The Open Atmospheric Science Journal, 2(1), 217-231. http://doi.org/10.2174/1874282300802010217

Haydu, J. (1999). Counter action frames: Employer repertoires and the union menace in the late nineteenth century. Social Problems, 46(3), 313-331. http://doi.org/10.2307/3097103

Heath, Y., \& Gifford, R. (2006). Free-market ideology and environmental degradation: The case of belief in global climate change. Environment and Behavior, 38(1), 48-71. http://doi.org/10.1177/0013916505277998 
Hewitt, L., \& McCammon, H. J. (2004). Explaining suffrage mobilization: Balance, neutralization, and range in collective action frames, 1892-1919. Mobilization: An International Quarterly, 9(2), 149-166.

How we work. (n.d.). Retrieved November 23, 2014, from http://350.org/about/how-we-work/

IPCC. (2014). 2014: Summary for policymakers. In C. B. Field, V. R. Barros, D. J. Dokken, K. J. Mach, M. D. Mastrandrea, T. E. Bilir, ... L. L. White (Eds.), Climate change 2014: Impacts, adaptation, and vulnerability. Part A: Global and sectoral aspects. Contribution of working group II to the fifth assessment report of the Intergovernmental Panel on Climate Change (pp. 1-32). Cambridge, United Kingdom and New York, NY: Cambridge University Press.

Johnston, H. (1995). A methodology for frame analysis: From discourse to cognitive schema. In B. Klandermans \& H. Johnston (Eds.), Social movements and culture (pp. 217-247). Minneapolis, MN: University of Minnesota Press. Johnston, H. (2005). Comparative frame analysis. In H. Johnston \& J. A. Noakes (Eds.), Frames of protest: Social movements and the framing perspective (pp. 237-260). Lanham, MD: Rowman \& Littlefield Publishers.

Kahneman, D. (2013). Thinking, fast and slow (Reprint edition). New York: Farrar, Straus and Giroux.

Klandermans, B. (1984). Mobilization and participation: Social-psychological expansions of resource mobilization theory. American Sociological Review, 49(5), 583-600. http://doi.org/10.2307/2095417 
Klandermans, B. (2014). Framing collective action. In K. Fahlenbrach, E. Sivertsen, \& R. Werenskjold (Eds.), Media and Revolt: Strategies and Performances from the 1960s to the Present (pp. 41-58). New York, NY: Berghahn Books.

Klandermans, B., \& van Stekelenburg, J. (2007). Individuals in movements: A social psychology of contention. In B. Klandermans \& C. Roggeband (Eds.), Handbook of Social Movements Across Disciplines (p. 157 - ?). Springer Science \& Business Media.

Leathers, D. (1986). Successful nonverbal communication : Principles and applications. New York: Macmillan.

Leiserowitz, A. (2006). Climate change risk perception and policy preferences: The role of affect, imagery, and values. Climatic Change, 77(1-2), 45-72. http://doi.org/10.1007/s10584-006-9059-9

Lorenzoni, I., Nicholson-Cole, S., \& Whitmarsh, L. (2007). Barriers perceived to engaging with climate change among the UK public and their policy implications. Global Environmental Change, 17(3-4), 445-459. http://doi.org/10.1016/j.gloenvcha.2007.01.004

Lorenzoni, I., \& Pidgeon, N. F. (2006). Public views on climate change: European and USA perspectives. Climatic Change, 77(1-2), 73-95. http://doi.org/10.1007/s10584-006-9072-z

Madestam, A., Shoag, D., Veuger, S., \& Yanagizawa-Drott, D. (2013). Do political protests matter? Evidence from the Tea Party movement. The Quarterly 
Journal of Economics, 128(4), 1633-1685.

http://doi.org/10.1093/qje/qjt021

Maibach, E., Roser-Renouf, C., \& Leiserowitz, A. (2009). Global warming's six Americas 2009: An audience segmentation analysis. Retrieved from http://trid.trb.org.proxy.lib.pdx.edu/view.aspx?id=889822

Mason, W., \& Suri, S. (2012). Conducting behavioral research on Amazon's Mechanical Turk. Behavior Research Methods, 44(1), 1-23. http://doi.org/10.3758/s13428-011-0124-6

Mayer, N. D., \& Tormala, Z. L. (2010). "Think" versus "feel” framing effects in persuasion. Personality and Social Psychology Bulletin, 36(4), 443-454. http://doi.org/10.1177/0146167210362981

McAdam, D., McCarthy, J. D., \& Zald, M. N. (1996). Comparative perspectives on social movements: Political opportunities, mobilizing structures, and cultural framings. New York, NY: Cambridge University Press.

McCright, A. M., \& Dunlap, R. E. (2011). The politicization of climate change and polarization in the American public's views of global warming, 2001-2010. Sociological Quarterly, 52(2), 155-194. http://doi.org/10.1111/j.15338525.2011.01198.x

Meyer, D. S. (2009). How social movements matter. In J. Goodwin \& J. Jasper (Eds.), The social movements reader: Cases and concepts (2nd ed., pp. 417-422). Chichester, UK: Wiley-Blackwell. 
Mills, C. W. (1940). Situated actions and vocabularies of motive. American Sociological Review, 5(6), 904-913. http://doi.org/10.2307/2084524

Mitra, R. (2013). From transformational leadership to leadership trans-formations: A critical dialogic perspective. Communication Theory (10503293), 23(4), 395-416. http://doi.org/10.1111/comt.12022

Moyer-Gusé, E., Jain, P., \& Chung, A. H. (2012). Reinforcement or reactance? Examining the effect of an explicit persuasive appeal following an entertainment-education narrative. Journal of Communication, 62(6), 10101027. http://doi.org/10.1111/j.1460-2466.2012.01680.x

Myers, T. A., Maibach, E., Roser-Renouf, C., Akerlof, K., \& Leiserowitz, A. A. (2013). The relationship between personal experience and belief in the reality of global warming. Nature Climate Change, 3(4), 343-347. http://doi.org/10.1038/nclimate1754

Nabi, R. L. (1999). A cognitive-functional model for the effects of siscrete negative emotions on information processing, attitude change, and recall. Communication Theory, 9(3), 292-320. http://doi.org/10.1111/j.14682885.1999.tb00172.x

Newport, F. (2014, April 4). Americans show low levels of concern on global warming. Retrieved October 8, 2014, from http://www.gallup.com/poll/168236/americans-show-low-levels-concernglobal-warming.aspx 
Noakes, J. A., \& Johnston, H. (2005). Frames of protest: A road map to a perspective. In H. Johnston \& J. A. Noakes (Eds.), Frames of protest: Social movements and the framing perspective (pp. 1-29). Lanham, MD: Rowman \& Littlefield Publishers.

Oreskes, N., \& Conway, E. M. (2010). Merchants of doubt: How a handful of scientists obscured the truth on issues from tobacco smoke to global warming (Reprint edition). New York: Bloomsbury Press.

Palmer, S. J. (1988). Charisma and abdication: A study of the leadership of Bhagwan Shree Rajneesh. Sociological Analysis, 49(2), 119-135. http://doi.org/10.2307/3711009

Petty, R. E., \& Cacioppo, J. T. (1986). The elaboration likelihood model of persuasion. Advances in Experimental Social Psychology, 19, 123-162.

Pew Research Center for the People \& the Press poll, Jan, 2014. (2014, January). Retrieved March 7, 2014, from http://www.people-press.org/questionsearch/

Printable materials: Climate impacts fact sheets. (n.d.). Retrieved March 10, 2014, from http://350.org/resources/materials/

Rabe, B. G., \& Borick, C. P. (2013, June 24). Winter 2013 freezes growth of American acceptance of global warming. Retrieved March 7, 2014, from http://www.brookings.edu/blogs/up-front/posts/2013/06/25-americanacceptance-global-warming-rabe-borick 
Saad, L. (2014, March 18). A steady 57\% in U.S. blame humans for global warming. Retrieved October 8, 2014, from http://www.gallup.com/poll/167972/steady-blame-humans-globalwarming.aspx

Scannell, L., \& Gifford, R. (2013). Personally relevant climate change: The role of place attachment and local versus global message framing in engagement. Environment and Behavior, 45(1), 60-85. http://doi.org/10.1177/0013916511421196

Scheufele, D. (1999). Framing as a theory of media effects. Journal of Communication, 49(1), 103-122. http://doi.org/10.1111/j.1460-2466.1999.tb02784.x

Schwartz, M. (1976). Radical protest and social structure: The Southern Farmers' Alliance and cotton tenancy, 1880-1890. Chicago, IL: University Of Chicago Press.

Shoenfeld, D. A. (2010, May 14). Statistical considerations for clinical trials and scientific experiments. Retrieved February 14, 2015, from http://hedwig.mgh.harvard.edu/sample_size/size.html\#power

Small, D. A., Loewenstein, G., \& Slovic, P. (2007). Sympathy and callousness: The impact of deliberative thought on donations to identifiable and statistical victims. Organizational Behavior and Human Decision Processes, 102(2), 143153. http://doi.org/10.1016/j.obhdp.2006.01.005

Snow, D. A., \& Benford, R. D. (1988). Ideology, frame resonance, and participant mobilization. International Social Movement Research, 1(1), 197-217. 
Snow, D. A., \& Benford, R. D. (1992). Master frames and cycles of protest. In A. D. Morris \& C. M. Mueller (Eds.), Frontiers in social movement theory (pp. 133155). New Haven, CT: Yale University Press.

Snow, D. A., Rochford, E. B., Jr., Worden, S. K., \& Benford, R. D. (1986). Frame alignment processes, micromobilization, and movement participation. American Sociological Review, 51(4), 464-481. http://doi.org/10.2307/2095581

Snow, D. A., Soule, S. A., \& Kriesi, H. (Eds.). (2004). The Blackwell Companion to Social Movements. Malden, MA: Blackwell Pub.

Tversky, A., \& Kahneman, D. (1974). Judgment under uncertainty: Heuristics and biases. Science, 185(4157), 1124-1131. http://doi.org/10.1126/science.185.4157.1124

Vicari, S. (2010). Measuring collective action frames: A linguistic approach to frame analysis. Poetics, 38(5), 504-525. http://doi.org/10.1016/j.poetic.2010.07.002

What we do. (n.d.). Retrieved November 22, 2014, from http://350.org/about/what-we-do/

Whitmarsh, L. (2008). Are flood victims more concerned about climate change than other people? The role of direct experience in risk perception and behavioural response. Journal of Risk Research, 11(3), 351-374. http://doi.org/10.1080/13669870701552235 
Zaval, L., Keenan, E. A., Johnson, E. J., \& Weber, E. U. (2014). How warm days increase belief in global warming. Nature Climate Change, 4(2), 143-147. http://doi.org/10.1038/nclimate2093

Zschau, T., Adams, A. E., \& Shriver, T. E. (2012). Reframing the biotechnology debate: The Deconstructive efforts of the Council for Responsible Genetics. Symbolic Interaction, 35(2), 221-239. http://doi.org/10.1002/symb.12

Zuo, J., \& Benford, R. D. (1995). Mobilization processes and the 1989 Chinese democracy movement. The Sociological Quarterly, 36(1), 131-156. 


\title{
Appendix A: IRB Approval
}

Post Office Box 751
Portiand, Oregon 97207-0751
Human Subjects Research Review Committee
$\begin{gathered}503-725-2227 \text { tel } \\ \text { hsrrc } 8 \text { lists.pdx.edu }\end{gathered}$

Date: February 27, 2015

To: Lauren Frank / Rebeca Smith

From: Karen Cellarius, HSRRC Chair

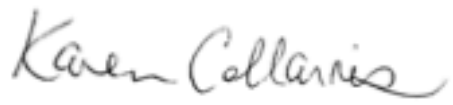

Re: HSRRC approval for your project titled. "The Effect of Motivational Frames on Social Movement Mobilization" HSRRC Proposal \# 153331

Review Type: Exempt, Category 2

\begin{abstract}
In accordance with your request, the Human Subjects Research Review Committee has reviewed your proposal referenced above for compliance with PSU and DHHS policies and regulations covering the protection of human subjects. The Committee is satisfied that your provisions for protecting the rights and welfare of all subjects participating in the research are adequate, and your project is approved. Please note the following requirements:
\end{abstract}

Approval: You are approved to conduct this research study after receipt of this approval letter; and the research must be conducted aceording to the plans and protocol submitted (approved copy enclosed).

Consent: Signed consent is waived from all participants in this study. A written consent statement is required.

Changes to Protocol: Any changes in the proposed study, whether to procedures, survey instruments, consent forms or cover letters, must be outlined and submitted to the Committee immediately. The proposed changes cannot be implemented before they have been reviewed and approved by the Committee.

Adverse Reactions and/or Unanticipated Problems: If any adverse reactions or unanticipated problems oceur as a result of this study, you are required to notify the Committee immediately. If the issue is serious, approval may be withdrawn pending an investigation by the Committee.

Completion of Study: Please notify the Committee as soon as your research has been completed. Study records, including protocols and signed consent forms for each participant, must be kept by the investigator in a secure location for three years following completion of the study (or per any requirements specified by the project's funding agency).

If you have questions of concems, please contact the Office of Research Integrity in the PSU RSP at 503-725-2227, 1600 SW $4^{42}$ Ave., Market Center Building, Suite 620. 


$\begin{array}{ll}\text { Post Office Box } 751 & 503-725-2227 \text { tel } \\ \text { Portland, Oregon } 97207-0751 & 503-725-8170 \text { fax } \\ \text { Human Subjects Research Review Committee } \\ \text { hsrre lists.pdx.edu }\end{array}$

Date: March 18, 2015

To: Lauren Frank / Rebecea Smith

From: Karen Cellarius, HSRRC Chair

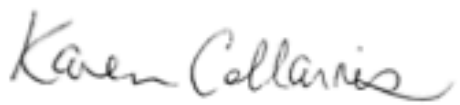

Re: HSRRC approval for your project titled, "The Effect of Motivational Frames on Social Movement Mobilization" HSRRC Proposal \# 153331

Review Type: Exempt, Category 2

The amendment submitted on $03 / 18 / 2015$ to the above protocol has been reviewed by the Portland State University Institutional Review Board and the Office of Research Integrity. This is a mirimal risk research protocol that continues to qualify for an exemption from IRB review under 45 CFR 46. 101(b)(2) for research involving the use of educational tests (cognitive, diagnostic, aptitude, achievement), survey procedures, interview procedures or observation of publie behavior.

Please note that you will not be required to submit continuing reviews for this protocol, however, you must submit any changes to the protocol to the Office of Research Integrity for assessment to verify that the protocol continues to qualify for exemption.

Your responsibility as a Principal Investigator also includes:

- Obtaining written documentation of the appropriate permissions from public school districts, institutions, agencies, or other organizations, etc., prior to conducting your research

- Notifying the Office of Research Integrity of any change in Principal Investigator

- Notifying the Office of Research Integrity of any changes to or supplemental funding

- Retaining copies of this determination, any signed consent forms, and related research materials for three years after conclusion of your study or the closure of your sponsored research, whichever comes last.

As with all Human Subject Research, exempt research is subject to periodie Post Approval Monitoring review.

If you have any questions regarding your protocol or the review process, please contact the Office of Research Integrity at HSRRCQpdx.edu or (503)725-2227.

Approved: $\quad$ Survey Instrument version 03/18/2015. 
Appendix B: Demographic Statistics

Race/Ethnic background (respondents could mark more than one field) ( $n=$ 375)

Caucasian: $n=310(82.7 \%)$

African American: $n=33(8.8 \%)$

Asian: $n=24$ (6.4\%)

Hispanic/Latino: $n=21$ (5.6\%)

American Indian/Alaskan Native/Pacific Islander: $n=10$ (2.7\%)

Education $(n=374)$

Bachelor's Degree: $n=143$ (38.1\%)

Some college: $n=94$ (25.1\%)

High school graduate or equivalency: $n=49$ (13.1\%)

2-year college degree: $n=41(10.9 \%)$

Master's degree: $n=33(8.8 \%)$

Professional degree: $n=6(1.6 \%)$

Doctoral degree or less than high school: $n=8(2.1 \%)$

Gender $(n=375)$

Female: $n=193(51.5 \%)$

Male: $n=178(47.5 \%)$

Other: $n=4(1.1 \%)$

Political party $(n=375)$

Democrat: $n=178(47.5 \%)$

No affiliation: $n=79(21.1 \%)$

Republican: $n=75(20 \%)$

Libertarian: $n=27$ (7.2\%)

Green or Constitution: $n=16(4.2 \%)$

Income $(n=373)$

$\$ 0-25,000: n=88(23.5 \%)$

$\$ 25,001-50,000: n=142(37.9 \%)$

$\$ 50,001-75,000: n=76(20.3 \%)$

$\$ 75,001-100,000: n=32(8.5 \%)$

$\$ 100,001-125,000: n=16(4.3 \%)$

$\$ 125,001-150,000: n=9(2.4 \%)$

Above $\$ 150,000: n=10(2.7 \%)$

Age $(n=372, M=39.21, S D=13.31)$ 


\section{Appendix C: Informed Consent}

You are invited to participate in a research study conducted by Rebecca Smith under the direction of Dr. Frank. This study attempts to collect information about how people feel about environmental issues. To be eligible to participate in this study you must be 18 years of age or older, currently live in the United States, and speak English fluently.

\section{Procedures}

If you decide to participate, you will be asked to complete the following questionnaire. The questionnaire will take approximately 20 minutes or less. You will need to be using a computer that can play videos with sound.

\section{Risks/Discomforts}

Risks are minimal for involvement in this study. However, you may feel uncomfortable when asked to share information about your feelings about environmental issues. You are welcome to skip any question that you feel uncomfortable answering.

\section{Benefits}

You may not receive any direct benefit from taking part in this study. However, it is hoped that through your participation, the study may help to increase knowledge which may help others in the future.

\section{Confidentiality}

All information that is obtained in connection with this study will be kept confidential and will only be reported in an aggregate format (by reporting only combined results and never reporting individual ones). All questionnaires will be concealed, and no one other than the research team will have access to them. At no point will your name be linked to your answers.

\section{Compensation}

You will be paid $\$ .50$ for your participation. Follow the directions at the end of the survey to enter the completion code into your Mechanical Turk account. Your personal information will not be linked to your survey responses. Mechanical Turk, the third party from whom you will receive compensation, will not have access to your survey responses and the research team will not have access to the personal information used to coordinate compensation.

\section{Participation}

Participation in this research study is completely voluntary. You have the right to withdraw at any time or refuse to participate entirely, and it will not affect your relationship with the research team or Portland State University in any way. 


\section{Questions about the Research}

If you have questions or concerns regarding this study, contact Rebecca Smith at Rebecca.smith@pdx.edu or Dr. Frank at lfrank@pdx.edu.

\section{Questions about your Rights as Research Participants}

If you have questions or concerns about your rights as a research subject, please contact the Portland State University Office of Research Integrity, 1600 SW 4th Avenue, Market Center Building, Suite 620, Portland, OR 97207; phone (503)7252227 or $1(877) 480-4400$.

By completing this survey, you are certifying that you are 18 years of age or older, a resident of the United States, and speak English fluently. In addition, you are certifying that you have read and understand the above information and agree to take part in the survey. Press the "Print" button below to keep a copy of this form for your own records.

If at this point you choose to continue in this research study, please click ">>" to continue. 


\section{Appendix D: Video Transcripts}

Video version 1 (https://www.youtube.com/watch?v=owPmkqxKlWU), total time: 3:08

\begin{tabular}{|c|c|c|c|}
\hline $\begin{array}{l}\text { Frame } \\
\#\end{array}$ & $\begin{array}{l}\text { Time } \\
\text { signature }\end{array}$ & Audio content & Frame Type \\
\hline 1 & $0: 14$ & $\begin{array}{l}\text { We are literally engaged in an } \\
\text { unprecedented experiment with the one } \\
\text { planet that we know of that can support } \\
\text { life. }\end{array}$ & Diagnostic \\
\hline 2 & $0: 24$ & $\begin{array}{l}\text { I remember when the weather channel } \\
\text { was this kind of like nice sleepy little } \\
\text { station. Now it's like a horror show. The } \\
\text { climate is being disrupted. That's not for } \\
\text { next year or a thousand years from now, } \\
\text { that's happening right now. }\end{array}$ & Diagnostic \\
\hline 3 & $0: 42$ & $\begin{array}{l}\text { We've proven beyond a doubt that } \\
\text { climate change is real, that the earth's } \\
\text { temperature is warming, that that } \\
\text { warming is predominantly caused by the } \\
\text { burning of fossil fuels and other human } \\
\text { activities, and that that additional } \\
\text { warming poses a significant threat. }\end{array}$ & Diagnostic \\
\hline 4 & 1:01 & $\begin{array}{l}\text { Just a year ago we passed } 400 \text { parts per } \\
\text { million of carbon dioxide in the } \\
\text { atmosphere. Now the preindustrial level } \\
\text { was about } 280 \text { parts per million, so } \\
\text { human society in the industrial era has } \\
\text { raised the level of co2 in the atmosphere } \\
\text { by about } 40 \% \text {. }\end{array}$ & Diagnostic \\
\hline 5 & $1: 20$ & $\begin{array}{l}\text { What all climate scientists will agree on is } \\
\text { that the entire atmosphere has changed, } \\
\text { all the atmospheric dynamics have } \\
\text { changed, so every event that happens } \\
\text { now is in the context of climate change, is } \\
\text { different from how it would have been. }\end{array}$ & Diagnostic \\
\hline 6 & $1: 36$ & $\begin{array}{l}\text { Scientists are screaming from the } \\
\text { rooftops about us avoiding going over a } 2 \\
\text { degree rise in the temperature of the } \\
\text { planet. Why are they so worried about } \\
\text { that? If we go over that amount of } \\
\text { warming, there are feedback loops in our } \\
\text { ecosystems, tipping points that climate }\end{array}$ & Diagnostic \\
\hline
\end{tabular}




\begin{tabular}{|l|l|l|l|}
\hline & & $\begin{array}{l}\text { change could spin out of control. And it } \\
\text { happens [snap] like that. }\end{array}$ & \\
\hline 7 & $1: 59$ & $\begin{array}{l}\text { If we really want to bring about a } \\
\text { limitation of temperature increase to no } \\
\text { more than 2 degrees Celsius, there is then } \\
\text { the need for an unprecedented level of } \\
\text { international cooperation. }\end{array}$ & Prognostic \\
\hline 8 & $2: 12$ & $\begin{array}{l}\text { They need to act on a binding global } \\
\text { agreement to reduce greenhouse gasses. } \\
\text { We can do that and create jobs at the } \\
\text { same time. }\end{array}$ & Prognostic \\
\hline 9 & $2: 21$ & $\begin{array}{l}\text { Part of what we're doing is moving } \\
\text { people from fossil fuels to the solutions } \\
\text { and also presenting them with economic } \\
\text { opportunities around the solutions. }\end{array}$ & Prognostic \\
\hline 10 & $2: 30$ & $\begin{array}{l}\text { People are reluctant to stand up and take } \\
\text { action if they don't see that the other } \\
\text { people around them are taking action. }\end{array}$ & Prognostic \\
\hline 11 & $2: 38$ & $\begin{array}{l}\text { All the big social movements in history } \\
\text { have had people in the streets; women's } \\
\text { voting rights, civil rights movement, and } \\
\text { even more recently on climate issues }\end{array}$ & Prognostic \\
\hline 12 & $2: 51$ & $\begin{array}{l}\text { Things change for lots of different } \\
\text { reasons. There's all kinds of dynamics, } \\
\text { but one central element is people being in } \\
\text { the streets. }\end{array}$ & Prognostic \\
\hline
\end{tabular}


Video version 2 (https://www.youtube.com/watch?v=Jx0Qa3cIHeA), total time: 2:59

\begin{tabular}{|c|c|c|c|}
\hline $\begin{array}{l}\text { Frame } \\
\#\end{array}$ & $\begin{array}{l}\text { Time } \\
\text { signature }\end{array}$ & Audio content & $\begin{array}{l}\text { Frame } \\
\text { Type }\end{array}$ \\
\hline 1 & $0: 14$ & $\begin{array}{l}\text { We are literally engaged in an unprecedented } \\
\text { experiment with the one planet that we know } \\
\text { of that can support life. }\end{array}$ & Diagnostic \\
\hline 2 & $0: 24$ & $\begin{array}{l}\text { I remember when the weather channel was } \\
\text { this kind of like nice sleepy little station. Now } \\
\text { it's like a horror show. The climate is being } \\
\text { disrupted. That's not for next year or a } \\
\text { thousand years from now, that's happening } \\
\text { right now. }\end{array}$ & Diagnostic \\
\hline 3 & $0: 42$ & $\begin{array}{l}\text { We've proven beyond a doubt that climate } \\
\text { change is real, that the earth's temperature is } \\
\text { warming, that that warming is predominantly } \\
\text { caused by the burning of fossil fuels and other } \\
\text { human activities, and that that additional } \\
\text { warming poses a significant threat. }\end{array}$ & Diagnostic \\
\hline 4 & $1: 02$ & $\begin{array}{l}\text { Scientists are screaming from the rooftops } \\
\text { about us avoiding going over a } 2 \text { degree rise in } \\
\text { the temperature of the planet. }\end{array}$ & Diagnostic \\
\hline 5 & $1: 09$ & $\begin{array}{l}\text { If we really want to bring about a limitation of } \\
\text { temperature increase to no more than } 2 \\
\text { degrees Celsius, there is then the need for an } \\
\text { unprecedented level of international } \\
\text { cooperation. }\end{array}$ & Prognostic \\
\hline 6 & $1: 21$ & $\begin{array}{l}\text { They need to act on a binding global } \\
\text { agreement to reduce greenhouse gasses. We } \\
\text { can do that and create jobs at the same time. }\end{array}$ & Prognostic \\
\hline 7 & $1: 30$ & $\begin{array}{l}\text { Part of what we're doing is moving people } \\
\text { from fossil fuels to the solutions and also } \\
\text { presenting them with economic opportunities } \\
\text { around the solutions. }\end{array}$ & Prognostic \\
\hline 8 & $1: 40$ & $\begin{array}{l}\text { People are reluctant to stand up and take } \\
\text { action if they don't see that the other people } \\
\text { around them are taking action. }\end{array}$ & Prognostic \\
\hline 9 & $1: 46$ & $\begin{array}{l}\text { All the big social movements in history have } \\
\text { had people in the streets; women's voting } \\
\text { rights, civil rights movement, and even more } \\
\text { recently on climate issues, our big successes } \\
\text { have happened when people left their homes } \\
\text { and went out in the streets. }\end{array}$ & Prognostic \\
\hline 10 & $2: 03$ & When I read a climate science article that talks & Motivation \\
\hline
\end{tabular}




\begin{tabular}{|l|l|l|l|}
\hline & & $\begin{array}{l}\text { about mid-century projections, what I read is } \\
\text { what's going to happen when my kid is 40. } \\
\text { That's what I see on the page. And for me, it is } \\
\text { absolutely my responsibility then to do } \\
\text { whatever it takes to protect my child. }\end{array}$ & al \\
\hline 11 & $2: 24$ & $\begin{array}{l}\text { This is the issue I will vote on. This is the issue } \\
\text { I will give money on. This is the issue I will } \\
\text { scream at the top of my lungs into a bullhorn } \\
\text { over. That is what moves politics. }\end{array}$ & $\begin{array}{l}\text { Motivation } \\
\text { al }\end{array}$ \\
\hline 12 & $2: 33$ & $\begin{array}{l}\text { There is no replacement, even in the digital } \\
\text { age, for human bodies next to each other } \\
\text { standing as one, hearts beating as one, voices } \\
\text { raised as one, making a political demand. }\end{array}$ & $\begin{array}{l}\text { Motivation } \\
\text { al }\end{array}$ \\
\hline 13 & $2: 45$ & $\begin{array}{l}\text { It's our chance to show the immense power of } \\
\text { people in solidarity. }\end{array}$ & $\begin{array}{l}\text { Motivation } \\
\text { al }\end{array}$ \\
\hline
\end{tabular}




\section{Appendix E: Survey Instrument}

Please provide the following background information about yourself.

What is your race (choose all that apply)?

- White/Caucasian

- Black/African American

- American Indian/Alaskan Native

a Asian

口 Pacific Islander

口 Hispanic/Latino

What level of education you have completed?

Less than high school

High school graduate or equivalency

Some college

2-year college degree

O Bachelor's degree

O Master's degree

Professional degree (JD, MD)

O Doctorate degree

What is your gender?

O Male

O Female

Other

What year were you born?

What political party do you most closely identify with?

O Constitution

O Democrat

O Green

O Libertarian

O Republican

O No affiliation

The following questions will give you a chance to tell us about your thoughts and experiences. Please answer openly and truthfully. Some questions refer to climate change. Please consider this to mean the same thing as global warming or global climate change.

Please indicate your response to the following question.

\begin{tabular}{|c|c|c|c|c|c|}
\hline & Very & Somewhat & Unsure & Not very & Not at all \\
\hline $\begin{array}{c}\text { How concerned } \\
\text { are you about } \\
\text { climate change? }\end{array}$ & 0 & 0 & 0 & 0 & 0 \\
\hline
\end{tabular}


How likely do you think it is that each of the following will occur during the next 50 years due to climate change?

\begin{tabular}{|c|c|c|c|c|c|}
\hline & Very Likely & Likely & Undecided & Unlikely & Very Unlikely \\
\hline $\begin{array}{l}\text { Worldwide, } \\
\text { many people's } \\
\text { standard of } \\
\text { living will } \\
\text { decrease. }\end{array}$ & $\mathrm{O}$ & $\mathrm{O}$ & $\mathrm{O}$ & $\mathrm{O}$ & $\mathrm{O}$ \\
\hline $\begin{array}{c}\text { Worldwide } \\
\text { water shortages } \\
\text { will occur. }\end{array}$ & $\mathrm{O}$ & $\mathrm{O}$ & 0 & $\mathrm{O}$ & $\mathrm{O}$ \\
\hline $\begin{array}{c}\text { Increased rates } \\
\text { of serious } \\
\text { disease } \\
\text { worldwide. }\end{array}$ & 0 & 0 & O & $\mathrm{O}$ & $\mathrm{O}$ \\
\hline $\begin{array}{l}\text { My standard of } \\
\text { living will } \\
\text { decrease. }\end{array}$ & $\mathrm{O}$ & O & O & $\mathrm{O}$ & $\mathrm{O}$ \\
\hline $\begin{array}{c}\text { Water } \\
\text { shortages will } \\
\text { occur where I } \\
\text { live. }\end{array}$ & $\mathrm{O}$ & $\mathrm{O}$ & 0 & 0 & $\mathrm{O}$ \\
\hline $\begin{array}{l}\text { My chance of } \\
\text { getting a } \\
\text { serious disease } \\
\text { will increase. }\end{array}$ & $\mathrm{O}$ & $\mathrm{O}$ & $\mathrm{O}$ & $\mathrm{O}$ & $\mathrm{O}$ \\
\hline
\end{tabular}

Please indicate your response to the following two questions.

\begin{tabular}{|c|c|c|c|c|c|}
\hline $\begin{array}{c}\text { How serious of } \\
\text { a threat do you } \\
\text { believe climate } \\
\text { change is to } \\
\text { non-human } \\
\text { nature? }\end{array}$ & Very & Somewhat & Unsure & Not very & Not at all \\
$\begin{array}{c}\text { How serious } \\
\text { are the current } \\
\text { impacts of } \\
\text { climate change } \\
\text { around the } \\
\text { world? }\end{array}$ & 0 & 0 & 0 & 0 \\
\hline
\end{tabular}

Please indicate your response to the following question.

\begin{tabular}{|c|c|c|c|c|c|}
\hline & Strongly Agree & Agree & $\begin{array}{c}\text { Neither Agree } \\
\text { nor Disagree }\end{array}$ & Disagree & $\begin{array}{c}\text { Strongly } \\
\text { Disagree }\end{array}$ \\
\hline $\begin{array}{c}\text { I have } \\
\text { personally } \\
\text { experienced the } \\
\text { effects of } \\
\text { climate change }\end{array}$ & 0 & 0 & 0 & 0 & 0 \\
\hline
\end{tabular}


We will now show you a short video. Following the video, there will be some additional survey questions. Please make sure your computer speakers are unmuted.

[The video transcripts are in Appendix D.]

Were you able to view and understand the video?

O Yes

O No

Did the video contain the following? Please answer to the best of your memory.

\begin{tabular}{|c|c|c|}
\hline $\begin{array}{c}\text { Someone mentions the weather } \\
\text { channel }\end{array}$ & Yes & No \\
$\begin{array}{c}\text { Someone mentions McDonalds } \\
\text { Som }\end{array}$ & 0 & 0 \\
\hline
\end{tabular}

The following questions will give you a chance to tell us more about your thoughts and experiences. Please answer openly and truthfully.

For each of the dimensions below, please click the button that best matches how you feel about climate change.

\begin{tabular}{|c|c|c|c|c|c|c|c|c|}
\hline & 1 & 2 & 3 & 4 & 5 & 6 & 7 \\
\hline Calming:Upsetting & 0 & 0 & 0 & 0 & 0 & 0 & 0 \\
Pleasant:Unpleasant & 0 & 0 & 0 & 0 & 0 & 0 & 0 \\
Nice:Awful & 0 & 0 & 0 & 0 & 0 & 0 & 0 \\
Comforting:Scary & 0 & 0 & 0 & 0 & 0 & 0 & 0 \\
Painless:Painful & 0 & 0 & 0 & 0 & 0 & 0 & 0 \\
\hline
\end{tabular}


Please indicate how much you agree or disagree with the following statements.

\begin{tabular}{|c|c|c|c|c|c|}
\hline & $\begin{array}{l}\text { Strongly } \\
\text { agree }\end{array}$ & Agree & $\begin{array}{l}\text { Neither } \\
\text { Agree nor } \\
\text { Disagree }\end{array}$ & Disagree & $\begin{array}{l}\text { Strongly } \\
\text { Disagree }\end{array}$ \\
\hline $\begin{array}{c}\text { Human activities have no } \\
\text { significant impact on global } \\
\text { temperatures }\end{array}$ & O & $\mathrm{O}$ & 0 & $\mathrm{O}$ & 0 \\
\hline $\begin{array}{l}\text { We can all do our bit to reduce } \\
\text { the effects of climate change }\end{array}$ & $\mathrm{O}$ & O & O & O & $\mathrm{O}$ \\
\hline $\begin{array}{l}\text { People should be made to } \\
\text { reduce their energy } \\
\text { consumption if it reduces } \\
\text { climate change }\end{array}$ & $\mathrm{O}$ & O & O & O & O \\
\hline $\begin{array}{l}\text { Radical changes to society are } \\
\text { needed to tackle climate change }\end{array}$ & 0 & $\mathrm{O}$ & $\mathrm{O}$ & O & 0 \\
\hline $\begin{array}{l}\text { There is no point in me doing } \\
\text { anything about climate change } \\
\text { because no one else is }\end{array}$ & O & O & O & 0 & $\mathrm{O}$ \\
\hline $\begin{array}{l}\text { Nothing I do on a daily basis } \\
\text { contributes to the problem of } \\
\text { climate change }\end{array}$ & O & O & O & O & O \\
\hline $\begin{array}{l}\text { Climate change is something } \\
\text { that frightens me }\end{array}$ & O & O & O & $\mathrm{O}$ & O \\
\hline $\begin{array}{l}\text { The effects of climate change } \\
\text { are likely to be catastrophic }\end{array}$ & 0 & O & 0 & O & 0 \\
\hline
\end{tabular}


Please indicate how much you agree or disagree with the following statements.

\begin{tabular}{|c|c|c|c|c|c|}
\hline & Strongly agree & Agree & $\begin{array}{c}\text { Neither Agree } \\
\text { nor Disagree }\end{array}$ & Disagree & $\begin{array}{l}\text { Strongly } \\
\text { Disagree }\end{array}$ \\
\hline $\begin{array}{l}\text { There are } \\
\text { simple things } \\
\text { that I can do } \\
\text { that will have a } \\
\text { meaningful } \\
\text { effect to } \\
\text { alleviate the } \\
\text { negative effects } \\
\text { of climate } \\
\text { change }\end{array}$ & $\mathrm{O}$ & $\mathrm{O}$ & $\mathrm{O}$ & $\mathrm{O}$ & $\mathrm{O}$ \\
\hline $\begin{array}{l}\text { I believe that } \\
\text { little things I } \\
\text { can do will } \\
\text { make a } \\
\text { difference to } \\
\text { alleviate the } \\
\text { negative effects } \\
\text { of climate } \\
\text { change }\end{array}$ & O & O & $\mathrm{O}$ & $\mathrm{O}$ & 0 \\
\hline $\begin{array}{l}\text { Even if I try to } \\
\text { do something } \\
\text { about climate } \\
\text { change, I doubt } \\
\text { if it will make } \\
\text { any difference }\end{array}$ & O & 0 & $\mathrm{O}$ & $\mathrm{O}$ & $\mathrm{O}$ \\
\hline $\begin{array}{l}\text { There is very } \\
\text { little I can do to } \\
\text { mitigate the } \\
\text { negative effect } \\
\text { of climate } \\
\text { change }\end{array}$ & O & 0 & $\mathrm{O}$ & 0 & 0 \\
\hline
\end{tabular}


Please indicate how much you agree or disagree with the following statements.

\begin{tabular}{|c|c|c|c|c|}
\hline $\begin{array}{c}\text { I plan to take } \\
\text { some actions to } \\
\text { stop climate } \\
\text { change }\end{array}$ & Strongly agree & Agree & $\begin{array}{c}\text { Neither Agree } \\
\text { nor Disagree }\end{array}$ & Disagree \\
$\begin{array}{c}\text { I personally do } \\
\text { Disagree }\end{array}$ \\
$\begin{array}{c}\text { not intend to do } \\
\text { much to stop } \\
\text { climate change }\end{array}$
\end{tabular}

For each of the dimensions below, please click the button that best matches how you feel about the speakers in the video.

\begin{tabular}{|c|c|c|c|c|c|c|c|}
\hline Competent:Incompetent & 0 & 0 & 0 & 0 & 0 & 0 & 0 \\
Qualified:Unqualified & 0 & 0 & 0 & 0 & 0 & 0 & 0 \\
Well-informed:Poorly & 0 & 0 & 0 & 0 & 0 & 0 & 0 \\
informed & 0 & 0 & 0 & 0 & 0 & 0 & 0 \\
Intelligent:Unintelligent & 0 & 0 & 0 & 0 & 0 & 0 \\
Honest:Dishonest & 0 & 0 & 0 & 0 & 0 & 0 & 0 \\
Straightforward:Evasive & 0 & 0 & 0 & 0 & 0 & 0 \\
Trustworthy:Untrustworthy & 0 & 0 & 0 & 0 & 0 & 0 & 0 \\
Sincere:Insincere & 0 & 0 & 0 & 0 & 0 & 0 & 0 \\
Assertive:Unassertive & 0 & 0 & 0 & 0 & 0 & 0 & 0 \\
Bold:Timid & 0 & 0 & 0 & 0 & 0 & 0 & 0 \\
Forceful:Meek & 0 & 0 & 0 & 0 & 0 & 0 & 0 \\
Active:Inactive & 0 & 0 & 0 & 0 & 0 & 0 & 0 \\
\hline
\end{tabular}


How frequently in the last three months have you heard or seen information about climate change that stated or implied:

\begin{tabular}{|c|c|c|c|c|c|c|c|}
\hline & Never & $\begin{array}{c}\text { Less than } \\
\text { Once a } \\
\text { Month }\end{array}$ & $\begin{array}{l}\text { Once a } \\
\text { Month }\end{array}$ & $\begin{array}{l}\text { 2-3 Times } \\
\text { a Month }\end{array}$ & $\begin{array}{l}\text { Once a } \\
\text { Week }\end{array}$ & $\begin{array}{l}\text { 2-3 Times } \\
\text { a Week }\end{array}$ & Daily \\
\hline $\begin{array}{l}\text { There's } \\
\text { nothing we } \\
\text { can do to fix } \\
\text { climate } \\
\text { change }\end{array}$ & $\mathrm{O}$ & 0 & 0 & 0 & O & 0 & O \\
\hline $\begin{array}{c}\text { Climate } \\
\text { change is not } \\
\text { a big enough } \\
\text { problem to } \\
\text { worry about }\end{array}$ & $\mathrm{O}$ & O & O & O & O & O & O \\
\hline $\begin{array}{l}\text { We need to } \\
\text { learn to adapt } \\
\text { to climate } \\
\text { change }\end{array}$ & 0 & 0 & 0 & O & O & O & $\mathrm{O}$ \\
\hline $\begin{array}{l}\text { We need to } \\
\text { develop } \\
\text { technological } \\
\text { solutions to } \\
\text { climate } \\
\text { change (e.g. } \\
\text { geo- } \\
\text { engineering) }\end{array}$ & 0 & 0 & 0 & 0 & $O$ & O & 0 \\
\hline $\begin{array}{l}\text { It's not up to } \\
\text { individuals to } \\
\text { help resolve } \\
\text { climate } \\
\text { change } \\
\text { because } \\
\text { others (e.g. } \\
\text { businesses, } \\
\text { organizations, } \\
\text { or } \\
\text { government) } \\
\text { are taking } \\
\text { care of it }\end{array}$ & 0 & 0 & 0 & 0 & 0 & 0 & 0 \\
\hline
\end{tabular}


How frequently in the last three months have you heard or seen information about climate change that stated or implied:

\begin{tabular}{|c|c|c|c|c|c|c|c|}
\hline & Never & $\begin{array}{c}\text { Less than } \\
\text { Once a } \\
\text { Month }\end{array}$ & $\begin{array}{c}\text { Once a } \\
\text { Month }\end{array}$ & $\begin{array}{c}2-3 \text { Times } \\
\text { a Month }\end{array}$ & $\begin{array}{c}\text { Once a } \\
\text { Week }\end{array}$ & $\begin{array}{c}\text { 2-3 Times } \\
\text { a Week }\end{array}$ & Daily \\
\hline $\begin{array}{c}\text { Climate } \\
\text { change } \\
\text { doesn't } \\
\text { exist }\end{array}$ & 0 & 0 & 0 & 0 & 0 & 0 \\
$\begin{array}{c}\text { Climate } \\
\text { change is } \\
\text { not a } \\
\text { problem } \\
\text { Climate } \\
\text { change is }\end{array}$ & 0 & 0 & 0 & 0 & 0 & 0 & 0 \\
$\begin{array}{c}\text { not caused } \\
\text { by humans }\end{array}$ & 0 & 0 & 0 & 0 & 0 & 0 \\
\hline
\end{tabular}

For the dimension below, please click the button that best matches how you feel about the video

\begin{tabular}{|c|c|c|c|c|c|c|c|c|}
\hline & 1 & 2 & 3 & 4 & 5 & 6 & 7 \\
\hline Informational:Motivational & $\mathrm{O}$ & $\mathrm{O}$ & $\mathrm{O}$ & $\mathrm{O}$ & $\mathrm{O}$ & $\mathrm{O}$ & 0 \\
\hline
\end{tabular}
What is your household income?
O $\$ 0-25,000$
O $\$ 25,001-50,000$
○ $\$ 50,001-75,000$
O $\$ 75,001-100,000$
O $\$ 100,001-125,000$
○ $\$ 125,001-150,000$
O $\$ 150,001-175,000$
O $\$ 175,001-200,000$
O Above $\$ 200,000$ 